\title{
Extraction and Hypolipidemic Activity of Low Molecular Weight Polysaccharides Isolated from Rosa Laevigata Fruits
}

\author{
Xuejiao Zhang $\mathbb{D}^{1,2}$ Yihong $H u \mathbb{D}^{2},{ }^{2}$ Chenzhong Jin $\mathbb{D}^{2},{ }^{2}$ and Weiguo Wu $\mathbb{D}^{1}$ \\ ${ }^{1}$ College of Food Science and Technology, Hunan Agricultural University, Changsha, 410128 Hunan, China \\ ${ }^{2}$ Collaborative Innovation Center for Field Weeds Control, Hunan University of Humanities, Science and Technology, Loudi, \\ 417000 Hunan, China
}

Correspondence should be addressed to Weiguo Wu; 207739863@qq.com

Received 18 June 2020; Revised 14 September 2020; Accepted 24 September 2020; Published 22 October 2020

Academic Editor: Maxim P. Evstigneev

Copyright (C) 2020 Xuejiao Zhang et al. This is an open access article distributed under the Creative Commons Attribution License, which permits unrestricted use, distribution, and reproduction in any medium, provided the original work is properly cited.

Three novel low molecular weight polysaccharides (RLP-1a, RLP-2a, and RLP-3a) with 9004, 8761, and 7571 Da were first obtained by purifying the crude polysaccharides from the fruits of a traditional Chinese medicinal herb Rosae Laevigatae. The conditions for polysaccharides from the R. Laevigatae fruit (RLP) extraction were optimized by the response surface methodology, and the optimal conditions were as follows: extraction temperature, $93^{\circ} \mathrm{C}$; extraction time, $2.8 \mathrm{~h}$; water to raw material ratio, 22 ; extraction frequency, 3. Structural characterization showed that RLP-1a consisted of rhamnose, arabinose, xylose, glucose, and galactose with the ratio of $3.14: 8.21: 1: 1.37: 4.90$, whereas RLP-2a was composed of rhamnose, mannose, glucose, and galactose with the ratio of $1.70: 1: 93.59: 2.73$, and RLP-3a was composed of rhamnose, arabinose, xylose, mannose, glucose, and galactose with the ratio of $6.04: 26.51: 2.05: 1: 3.17: 31.77$. The NMR analyses revealed that RLP-1a, RLP-2a, and RLP-3a contained 6, 4, and 6 types of glycosidic linkages, respectively. RLP-1a and RLP-3a exhibited distinct antioxidant abilities on the superoxide anions, 1,1-diphenyl-2-picrylhydrazyl (DPPH), and hydroxyl radicals in vitro. RLPs could decrease the serum lipid levels, elevate the serum high-density lipoprotein cholesterol levels, enhance the antioxidant enzymes levels, and upregulate of FADS2, ACOX3, and SCD-1 which involved in the lipid metabolic processes and oxidative stress in the high-fat diet-induced rats. These results suggested that RLPs ameliorated the high-fat diet- (HFD-) induced lipid metabolism disturbance in the rat liver through the peroxisome proliferator-activated receptor (PPAR) signaling pathway. Low molecular weight polysaccharides of RLP could be served as a novel potential functional food for improving hyperlipidemia and liver oxidative stress responses.

\section{Introduction}

Rosae Laevigatae is a perennial shrub belonging to the Rosaceae family, and its fruits have been used widely as edible food and medicinal herb in the tropical and subtropical areas of Asia for thousands of years. The fruits are rich in vitamin C, polysaccharides, triterpenoid acids, steroids, polyphenols, saponins, and flavonoids $[1,2]$. In China, they are used as the foodstuff in the traditional brewing of wine, for the extraction of brown pigments, and the preparation of the healthy vinegar-based beverages [3]. Previous studies also indicated that this medicinal plant had the effects on antioxidation [4], antiapoptosis [5], reducing inflammation [2], inhibiting arterial sclerosis [1], and hepatoprotective activity [6]. Polysaccharides, flavonoids, and saponins from these fruits have been confirmed as primary active constituents by previous pharmacological researches $[7,8]$. Among them, polysaccharides are the main components with approximately $260.5 \mathrm{mg} / \mathrm{g}$ in total and are of great importance to humans [1], but few documents on the extraction, characterization, and biological activities of the polysaccharides from $R$. laevigata fruits (RLP) have been published.

Plant polysaccharides widely exist in plant organs including flowers, roots, leaves, and fruits. In recent years, plant polysaccharides have been attracting great attention due to their natural and nontoxic properties with no side effects. Their bioactivities and pharmacological functions were identified in terms of antioxidation [9], anticancer [10], antiinflammatory [11], antimicrobial [12], hepatoprotective [13], hypolipidemic, and hypoglycemic activities [14, 15], 
indicating a wide application prospect in medicine. However, early studies have shown that the biological activity of polysaccharide was closely related to its chemical structure, molecular weight, and monosaccharide composition [16]. High molecular weight of polysaccharides limits their applications owing to their physical properties including low solubility and complex structures [17]. The molecular weight of polysaccharides over $10 \mathrm{kDa}$ in weight had poor solubility, was not conducive to the digestion and absorption in vivo, and subdued the biological activities, whereas the low molecular weight polysaccharides less than $10 \mathrm{kDa}$ in weight had relatively higher activities and were of greater significance to human health [18-20]. Polysaccharides with larger molecular weight appeared high apparent viscosity, poor water solubility, and complex structures and conformations [20]. They are difficult to enter into cells or attach to the receptors to exert their biological effects [21]. The clinical application of natural polysaccharides has been restricted due to their large molecular weights and low solubility. The separation of polysaccharides with low molecular weight is becoming a hotspot.

At present, there are no reports on the separation of polysaccharides with low molecular weight less than $10 \mathrm{kDa}$ from the R. Laevigatae fruits (RLPs). The main researches focused on the hypolipidemic, antioxidant, and immunomodulatory activities of high molecular weight polysaccharides of R. Laevigatae fruits $[1,2]$. It is also unclear whether RLPs have better antioxidant or hypolipidemic activities. Thus, a detailed structural, antioxidant, and hypolipidemic analyses of RLPs are necessary to support their potential application for functional food ingredients.

In this study, three low molecular weight RLPs, namely, RLP-1a, RLP-2a, and RLP-3a, were first isolated from R. Laevigatae fruits by fractionation and purification. The primary chemical structures of RLP-1a, RLP-2a, and RLP-3a were characterized by the Fourier transform infrared (FT-IR), gas chromatography-mass spectrometry (GC-MS), and nuclear magnetic resonance (NMR) analyses. The antioxidant and hypolipidemic activities of RLPs composed of RLP-1a, RLP-2a, and RLP-3a were evaluated by investigating their effects on lipid profiles, antioxidant enzyme activities, and lipid metabolic gene expressions in high-fat diet(HFD-) induced rat. The study could provide implications for the utilization of low molecular weight RLPs in functional food to improve blood lipid metabolism.

\section{Materials and Methods}

2.1. Materials and Chemicals. The R. Laevigatae fruits were purchased from a local market in Hunan, China. L-ascorbic acid and 1,1-diphenyl-2-picrylhydrazyl (DPPH) were purchased from Sigma-Aldrich (St. Louis, Missouri, USA). Diethylaminoethyl- (DEAE-) cellulose and Sepharose CL$4 \mathrm{~B}$ were purchased from Whatman (Sanford, ME, UK). All other chemicals used were of analytical-reagent grade.

2.2. Extraction of Polysaccharides from R. Laevigatae Fruits. After dried, crushed, and screened for 60 meshes, the R. Laevigatae fruit powders were obtained. The powders were defatted with petroleum ether (boiling point $60-90^{\circ} \mathrm{C}$ ) and then pretreated with $90 \%$ ethanol $(\mathrm{v} / \mathrm{v})$ for several times to remove pigments, monosaccharides, and phenolic compounds until the solution was colorless. After centrifuged at $4000 \times \mathrm{g}$ for $20 \mathrm{~min}$, the sediment was vacuum-dried to constant weight. Each dried and pretreated sample $(10 \mathrm{~g})$ was extracted with deionized water at the designated extraction conditions. The conditions were controlled by varying temperature, extraction time, water to raw material ratio, and extraction frequency. After centrifugation at $4000 \times \mathrm{g}$ for $20 \mathrm{~min}$, the supernatant was dialyzed for $48 \mathrm{~h}$ against deionized water to remove oligosaccharides. The liquid obtained in a dialysis bag was precipitated by overnight incubation against ethanol to a final concentration of $80 \%(\mathrm{v} / \mathrm{v})$. The precipitate was collected by centrifugation at $4000 \times \mathrm{g}$ for $15 \mathrm{~min}$ and deproteinated by Sevag method for five times $[1,22]$. After lyophilized, the polysaccharide content was measured using the phenol-sulfuric acid method with Dglucose as standard [23].

2.3. Response Surface Methodology. Four variables $\left(X_{1}\right.$, extraction temperature; $X_{2}$, extraction time; $X_{3}$, water to raw material ratio; and $X_{4}$, extraction frequency) at five levels $\left(X_{1}\right.$ with $80,85,90,95$, and $100^{\circ} \mathrm{C} ; X_{2}$ with $1,1.5,2,2.5$, and $3 \mathrm{~h} ; X_{3}$ with $1: 16,1: 18,1: 20,1: 22$, and $1: 24$; and $X_{4}$ with 1 , $2,3,4$, and 5) were performed according to the experiment results of single factor effect on polysaccharide extraction. Thirty independent variable combinations were designed by central composite design (CCD), each of which was performed in triplicate in a randomized order. The response value of each trial was calculated as the average of the duplicates. The CCD data were analyzed by the multiple regression.

2.4. Isolation and Purification. About $100 \mathrm{~g}$ dried powder of $R$. Laevigatae fruits was used as raw material. After defatted and pretreated, the polysaccharides were extracted with $2 \mathrm{~L}$ of distilled water at $90^{\circ} \mathrm{C}$ for $2 \mathrm{~h}$. Deproteinated by Sevag method and dialyzed to intercept molecular weight greater than $3500 \mathrm{Da}$, the liquid obtained in the dialysis bag was precipitated overnight against ethanol to a final concentration of $30 \%(\mathrm{v} / \mathrm{v})$. After centrifugation at $4000 \times \mathrm{g}$ for $20 \mathrm{~min}$, the supernatant was collected and further precipitated overnight to a final concentration of $50 \%(\mathrm{v} / \mathrm{v})$. The supernatant was treated as above with ethanol to a final concentration of $80 \%(\mathrm{v} / \mathrm{v})$. After centrifuged at $4000 \times \mathrm{g}$ for $20 \mathrm{~min}$ and freeze-dried, the crude RLP was obtained.

Approximately $30 \mathrm{mg}$ crude RLP in $10 \mathrm{~mL}$ water was loaded onto a diethylaminoethyl- (DEAE-) cellulose column $(2.6 \times 80 \mathrm{~cm})$ preequilibrated with water and eluted in $\mathrm{NaCl}$ gradient solution $(0-1.5 \mathrm{M})$ at the flow rate of $1 \mathrm{~mL} / \mathrm{min}$. Each elution tube was collected and monitored for carbohydrate content as abovementioned. Finally, the tubes of each carbohydrate-positive fraction were pooled together separately, then dialyzed and lyophilized. The products were further purified by gel filtration chromatography on a Sepharose CL-4B column $(2.6 \times 80 \mathrm{~cm})$ with water at a flow rate of $1 \mathrm{~mL} / \mathrm{min}$, and the different fractions were pooled together 
separately, dialyzed, and lyophilized, and then the purified RLPs were obtained.

\subsection{RLP Analysis}

2.5.1. Molecular Weight Determination. The homogeneity and molecular weight of the purified RLPs were determined by high performance gel permeation chromatography (HPGPC), which was performed on a HPLC-1525 liquid chromatography instrument (Waters, Massachusetts, USA) with a TSK-GEL G5000 PWXL column $(7.8 \times 300 \mathrm{~mm})$ series connected with a TSK-GEL G3000 PWXL column $(7.8 \times 300 \mathrm{~mm})$ (Tosoh, Tokyo, Japan). The column was eluted with $0.02 \mathrm{M} \mathrm{Na}_{2} \mathrm{SO}_{4}$ with a flow rate of $0.6 \mathrm{~mL} / \mathrm{min}$ and detected by a RID-2410 detector. The sample $(2 \mathrm{mg})$ was dissolved in the mobile phase and centrifuged, and the volume of $20 \mu \mathrm{l}$ sample was injected in each run. The molecular weight was estimated by reference to the calibration curve made from a standard dextran solution consisting $\mathrm{T}$ 400, T-300, T-200, T-100, T-40, T-20, T-10, and T-5 [24].

2.5.2. Monosaccharide Composition Analysis. Monosaccharide compositions of the purified RLPs were estimated through gas chromatography-mass spectrometry (GC-MS) 6890-5975 (Agilent Co., Colorado Springs, CO, USA). The sample $(10 \mathrm{mg})$ was hydrolyzed in $2 \mathrm{~mL}$ of $4 \mathrm{M}$ trifluoroacetic acid (TFA) for $3 \mathrm{~h}$ at $120^{\circ} \mathrm{C}$ in a sealed glass tube. The hydrolysate was evaporated to dry under $\mathrm{N}_{2}$ and dissolved in $1 \mathrm{~mL}$ pyridine with $10 \mathrm{mg}$ hydroxylamine at $90^{\circ} \mathrm{C}$ for $30 \mathrm{~min}$. Afterward, $1 \mathrm{~mL}$ acetic anhydride was added to the solution and allowed to react at $90^{\circ} \mathrm{C}$ for $30 \mathrm{~min}$ before being filtered through $0.22 \mu \mathrm{m}$ syringe filters (Whatman, Sanford, ME, UK). The final product was analyzed by GC-MS. As external standards, the following monosaccharides were converted to their acetylated derivatives and analyzed: rhamnose, ribose, fucose, arabinose, xylose, mannose, glucose, galactose, and fructose.

2.5.3. Ultraviolet and Fourier Transformation Infrared Spectrum Analysis. Ultraviolet spectra of the purified RLPs were obtained on a T60 UV-Vis spectrophotometer (Shimadzu, Kyoto, Japan). The scanning range was 190-600 nm at $5 \mathrm{~nm}$ interval, resulting in 82 points spectra for each sample.

Fourier transformation infrared spectra (FT-IR) for the samples were recorded on a Nicolet 6700 IR spectrometer (Thermo Fisher Scientific, Waltham, MA, USA). The dried samples were ground with spectroscopic grade $\mathrm{KBr}$ powder for FT-IR measurement in the wavenumber range of 4000$400 \mathrm{~cm}^{-1}$ [24].

2.5.4. Nuclear Magnetic Resonance Spectroscopy. Purified RLP (60 mg) was dissolved in $0.5 \mathrm{~mL} \mathrm{D}_{2} \mathrm{O}$ for the nuclear magnetic resonance spectroscopy (NMR) analysis. Spectra were recorded by a Bruker DRX-600 spectrometer (Rheinstetten, Germany) at $25^{\circ} \mathrm{C}$. The one-dimensional $\left({ }^{1} \mathrm{H}\right.$ and ${ }^{13} \mathrm{C}$ ) NMR was performed using the standard Bruker software TopSpin. ${ }^{1} \mathrm{H}$ chemical shifts were referenced to residual $\mathrm{D}_{2} \mathrm{O}$ at $4.71 \mathrm{ppm}$ at $25^{\circ} \mathrm{C}$ as the internal standard, whereas ${ }^{13} \mathrm{C}$ chemical shifts were determined with acetone $\left(\delta^{1} \mathrm{H}\right.$
$2.19 \mathrm{ppm}$ and ${ }^{13} \mathrm{C} 31.50 \mathrm{ppm}$ ) that was calibrated externally, and the chemical shift units were expressed as ppm [25].

2.5.5. Morphological Analysis. The morphology of the purified RLPs was analyzed by an environment scanning electron microscope (JSM-7500F, JEOL, Japan). The dried powder of samples was placed on tapes, sputtered with gold, and determined with an acceleration voltage of $5 \mathrm{kV}$.

\subsection{In Vitro Antioxidant Activity Assays}

2.6.1. Hydroxyl Radical Scavenging Assay. The scavenging activity of samples against hydroxyl radicals was measured as described [26] with some modifications. Various samples $(1.0 \mathrm{~mL}$ each) at the concentrations of $0.2,0.4,0.6,0.8,1.0$, and $0.2 \mathrm{mg} / \mathrm{mL}$ were mixed with $1 \mathrm{~mL}$ of $1.5 \mathrm{mM}$ ethylenediaminetetraacetic acid-Fe(II), $1 \mathrm{~mL}$ of $10 \mathrm{mM} \mathrm{H}_{2} \mathrm{O}_{2}$, and $1 \mathrm{~mL}$ of $9 \mathrm{mM}$ salicylic acid. After incubation at $37^{\circ} \mathrm{C}$ for $60 \mathrm{~min}$, the absorbance of the solution was measured at $560 \mathrm{~nm}$ with ascorbic acid as the positive control. The scavenging activity of the sample toward hydroxyl radicals was calculated using the following formula:

$$
\text { Scavenging rate }(\%)=\left(1-\frac{A_{i}}{A_{0}}\right) \times 100,
$$

where $A_{0}$ was the blank absorbance, and $A_{i}$ was the absorbance of sample or ascorbic acid.

2.6.2. DPPH Scavenging Assay. The scavenging activity of samples against DPPH radicals was determined according to the method [26] with modifications. The reaction mixture comprised $1 \mathrm{~mL}$ DPPH $(0.1 \mathrm{mM}$ in ethanol $)$ and $1 \mathrm{~mL}$ sample solution $(0.2,0.4,0.6,0.8,1.0$, and $1.2 \mathrm{mg} / \mathrm{mL})$. The mixture was incubated at $25^{\circ} \mathrm{C}$ for $30 \mathrm{~min}$ in dark, and the absorbance of the mixture was determined at $517 \mathrm{~nm}$, and ascorbic acid was used as the positive control, and $95 \%$ ethanol was the blank control. The DPPH radical scavenging ability was calculated using formula (1).

2.6.3. Superoxide Radical Scavenging Assay. The scavenging activity for superoxide anions radical was performed with the methods $[9,27]$ with modifications. About $4.5 \mathrm{~mL}$ $50 \mathrm{mM}$ Tris-HCl buffer ( $\mathrm{pH} 8.2$ ) was mixed with $4.2 \mathrm{~mL}$ of deionized water. After incubation at $25^{\circ} \mathrm{C}$ for $20 \mathrm{~min}, 1 \mathrm{~mL}$ sample solution and $0.4 \mathrm{~mL}$ pyrogallic acid were added to the mixture. The mixture was rapidly shaken and incubated at $25^{\circ} \mathrm{C}$ for $5 \mathrm{~min}$. Subsequently, $8 \mathrm{mM} \mathrm{HCl}$ was added to the mixture to terminate the reaction. The absorbance of the mixture was measured at $320 \mathrm{~nm}$ with ascorbic acid as the positive control. The scavenging ability of the sample toward superoxide radicals was calculated using formula (1).

2.7. Design of Animal Experiments. Normal chow and purified high-fat diet ( $45 \%$ fat) were purchased from MediScience Ltd. (Yangzhou, China). Eight-week-old male rats were provided by Hunan SJA Laboratory Animal Co., Ltd. They were acclimatized in the controlled environment (temperature 22 $\pm 2^{\circ} \mathrm{C} ; 60 \pm 10 \%$ humidity; and a $12 \mathrm{~h} / 12 \mathrm{~h}$ light/dark cycle) with free access to water and standard chow. All rats were 
fed for one week and designated into four groups, with ten rats on each group, namely, the control group $(\mathrm{CN})$, the high-fat diet group (HFD), the high-dose RLP group (HRLP), and the low-dose RLP group (LRLP). The CN group was fed with normal chow and treated with $5 \%$ acacia gum solution. The HFD group was fed with HFD and treated with $5 \%$ acacia gum solution. The HRLP group and LRLP group were fed with HFD + $800 \mathrm{mg} / \mathrm{kg}$ RLP and HFD + $200 \mathrm{mg} / \mathrm{kg}$ RLP, respectively. After 12 weeks, the rats were sacrificed by cervical dislocation after anesthesia. The blood samples were centrifuged at $7000 \times \mathrm{g}$ for $10 \mathrm{~min}$ at $4^{\circ} \mathrm{C}$. Serum was immediately collected, frozen, and stored at $-80^{\circ} \mathrm{C}$ until analysis [28]. Tissues were snap frozen by liquid nitrogen and preserved in the $-80^{\circ} \mathrm{C}$ refrigerator for further analysis.

2.8. Biochemical Determination of Serum and Liver. The serum total cholesterol (TC), triglycerides (TG), highdensity lipoprotein (HDL-C), low-density lipoprotein (LDL-C), the weak absorption peaks at 2935, and free fatty acid (FFA) concentrations were tested by an automatic biochemical analyzer (Beckman Coulter, Atlanta, Georgia, USA). The levels of alanine transaminase (ALT), aspartate transaminase (AST), and glutamyl transpeptidase (GGT) in serum and the contents of catalase (CAT), superoxide dismutase (SOD), and glutathione oxidase (GSH-Px) in liver supernatant were tested following instructions of the kits (Beckman Coulter, Beverly, USA).

2.9. Transcriptome Analysis. Total RNA of liver tissue was extracted by Trizol method. RNA integrity was assessed using the RNA Nano 6000 Assay Kit of the Bioanalyzer 2100 system (Agilent Technologies, CA, USA). PCR was performed with Phusion High-Fidelity DNA polymerase, Universal PCR primers, and Index (X) Primer. The PCR products were purified by AMPure XP system (Beckman Coulter, Beverly, USA), and the library quality was assessed on the Agilent Bioanalyzer 2100 system.

Differential expression analyses of two conditions/groups (two biological replicates per condition) were performed using the DESeq2 R package. The resulting $P$ values were adjusted using the Benjamini and Hochberg's approach for controlling the false discovery rate. Genes with an adjusted $P$ value $<0.05$ found by DESeq 2 were assigned as differentially expressed. Corrected $P$ value $<0.05$ and absolute fold change $>2$ were set as the threshold for significantly differential expression.

Gene ontology (GO) enrichment analysis of differentially expressed genes was implemented by the cluster Profiler R package, in which gene length bias was corrected. GO terms with corrected P-value less than 0.05 were considered significantly enriched by differential expressed genes. We used cluster Profiler R package to test the statistical enrichment of differential expression genes in KEGG pathways. Differentially expressed genes identified by transcriptome analysis were validated using qRT-PCR.

2.10. Statistical Analysis. Design Expert 8.0.6 was used to design the response surface experiment. Unless otherwise indicated, the results were expressed as mean \pm SD (standard deviation). SPSS 17.0 (SPSS Inc., Chicago, IL, USA) was used to analyze the experimental data by one-way ANOVA. Confidence levels for statistical significance were set at $P<0.05$.

\section{Results and Discussion}

3.1. Optimization of the Extraction Conditions for Polysaccharides from $R$. Laevigatae Fruit. The design matrix and corresponding results obtained from CCD for determining the effects of four independent variables $X_{1}, X_{2}, X_{3}$, and $X_{4}$, respectively, were listed in Table 1 . The results showed that the extraction rate ranged from $7.19 \%$ to $9.49 \%$. The multiple regression analysis performed on the experimental data revealed that the relationship between the response and test variables was described by the following secondorder polynomial equation:

$$
\begin{aligned}
Y(\%)= & -55.329+0.912 X_{1}-1.974 X_{2}+1.553 X_{3}+5.600 X_{4} \\
& -0.016 X_{1} X_{2}+0.023 X_{1} X_{3}+0.004 X_{1} X_{4}+0.288 X_{2} X_{3} \\
& -0.288 X_{2} X_{4}-0.147 X_{3} X_{4}-0.007 X_{1}^{2}-0.284 X_{2}^{2} \\
& -0.092 X_{3}^{2}-0.399 X_{4}^{2}
\end{aligned}
$$

where $Y$ : the extraction yield (\%); $X_{1}$ : extraction temperature $\left({ }^{\circ} \mathrm{C}\right) ; X_{2}$ : extraction time $(\mathrm{h}) ; X_{3}$ : water to raw material ration $(\mathrm{mL} / \mathrm{g}) ; X_{4}$ : extraction frequency.

The fitting statistics of the extraction rate $Y$ to the selected quadratic model were shown in Table 2. ANOVA of the quadratic regression model showed that the determination coefficient $R^{2}$ was 0.9128 , indicating that only $8.72 \%$ of the total variation could not be explained by the model. The adjusted determination coefficient $\left(R_{\mathrm{adj}}{ }^{2}=0.8315\right)$ also confirmed that the model was highly significant. The model was thus adequate for prediction within the range of experimental variables. The regression coefficient values were listed in the table. $P$ values were calculated to determine the significance of various coefficients and described patterns of interaction between variables. A smaller $P$ value indicated a more significant corresponding coefficient. Statistical analysis showed that extraction time $\left(X_{2}\right)$ was the most important independent variable that affected the extraction rate, followed by the extraction temperature $\left(X_{1}\right)$, the extraction frequency $\left(X_{4}\right)$, and the water to raw material ratio $\left(X_{3}\right)$.

The $3 \mathrm{D}$ response surface and contour plots of the CCD were obtained using the Design Expert Software (version 8.0.6). The effects and interactions of the four factors in response surface were directly reflected by the steepness of the trend of response surface curve and the density of contour plots. As shown in Figure 1(a), the response surface of extraction time was relatively steep and the contour lines were relatively dense. However, the response surface of extraction temperature was relatively smooth, and the contour lines were relatively sparse. Effect of extraction time on the extraction yield of RLP was more significant than that of the extraction temperature. The interaction between extraction temperature and water to raw material ratio on the extraction yield was shown in Figure 1(b). Similarly, the 
TABLE 1: Response surface central composite design and results for extraction yield of RLP.

\begin{tabular}{|c|c|c|c|c|c|}
\hline $\begin{array}{l}\text { Std. } \\
\text { order }\end{array}$ & $\begin{array}{c}X_{1}, \text { extraction } \\
\text { temperature }\left({ }^{\circ} \mathrm{C}\right)\end{array}$ & $\begin{array}{l}X_{2} \text {, extraction time } \\
(\mathrm{h})\end{array}$ & $\begin{array}{c}X_{3} \text {, water to raw material ration } \\
(\mathrm{mL} / \mathrm{g})\end{array}$ & $\begin{array}{l}X_{4} \text {, extraction } \\
\text { frequency }\end{array}$ & $\begin{array}{c}\text { Extraction yield of RLP } \\
(\%)\end{array}$ \\
\hline 1 & $-1(85)$ & $-1(1.5)$ & $-1(1: 18)$ & $-1(2)$ & $7.77 \pm 0.33$ \\
\hline 2 & $-1(85)$ & $-1(1.5)$ & $-1(1: 18)$ & $1(4)$ & $8.97 \pm 0.39$ \\
\hline 3 & $-1(85)$ & $-1(1.5)$ & $1(1: 22)$ & $-1(2)$ & $7.91 \pm 0.14$ \\
\hline 4 & $-1(85)$ & $-1(1.5)$ & $1(1: 22)$ & $1(4)$ & $7.19 \pm 0.35$ \\
\hline 5 & $-1(85)$ & $1(2.5)$ & $-1(1: 18)$ & $-1(2)$ & $8.38 \pm 0.25$ \\
\hline 6 & $-1(85)$ & $1(2.5)$ & $-1(1: 18)$ & $1(4)$ & $8.27 \pm 0.03$ \\
\hline 7 & $-1(85)$ & $1(2.5)$ & $1(1: 22)$ & $-1(2)$ & $8.41 \pm 0.17$ \\
\hline 8 & $-1(85)$ & $1(2.5)$ & $1(1: 22)$ & $1(4)$ & $8.26 \pm 0.15$ \\
\hline 9 & 1(95) & $-1(1.5)$ & $-1(1: 18)$ & $-1(2)$ & $7.71 \pm 0.02$ \\
\hline 10 & 1(95) & $-1(1.5)$ & $-1(1: 18)$ & $1(4)$ & $8.97 \pm 0.37$ \\
\hline 11 & 1(95) & $-1(1.5)$ & $1(1: 22)$ & $-1(2)$ & $8.2 \pm 0.04$ \\
\hline 12 & 1(95) & $-1(1.5)$ & $1(1: 22)$ & $1(4)$ & $8 \pm 0.02$ \\
\hline 13 & $1(95)$ & $1(2.5)$ & $-1(1: 18)$ & $-1(2)$ & $7.62 \pm 0.2$ \\
\hline 14 & $1(95)$ & $1(2.5)$ & $-1(1: 18)$ & $1(4)$ & $8.01 \pm 0.12$ \\
\hline 15 & 1(95) & $1(2.5)$ & $1(1: 22)$ & $-1(2)$ & $9.49 \pm 0.1$ \\
\hline 16 & $1(95)$ & $1(2.5)$ & $1(1: 22)$ & $1(4)$ & $8.6 \pm 0.21$ \\
\hline 17 & $-2(80)$ & $0(2)$ & $0(1: 20)$ & $0(3)$ & $8.09 \pm 0.44$ \\
\hline 18 & $2(100)$ & $0(2)$ & $0(1: 20)$ & $0(3)$ & $8.63 \pm 0.02$ \\
\hline 19 & $0(90)$ & $-2(1)$ & $0(1: 20)$ & $0(3)$ & $8.38 \pm 0.03$ \\
\hline 20 & $0(90)$ & $2(3)$ & $0(1: 20)$ & $0(3)$ & $9.24 \pm 0.36$ \\
\hline 21 & $0(90)$ & $0(2)$ & $-2(1: 16)$ & $0(3)$ & $7.53 \pm 0.31$ \\
\hline 22 & $0(90)$ & $0(2)$ & $2(1: 24)$ & $0(3)$ & $7.7 \pm 0.36$ \\
\hline 23 & $0(90)$ & $0(2)$ & $0(1: 20)$ & $-2(1)$ & $7.22 \pm 0.03$ \\
\hline 24 & $0(90)$ & $0(2)$ & $0(1: 20)$ & $2(5)$ & $7.78 \pm 0.03$ \\
\hline 25 & $0(90)$ & $0(2)$ & $0(1: 20)$ & $0(3)$ & $9.36 \pm 0.07$ \\
\hline 26 & $0(90)$ & $0(2)$ & $0(1: 20)$ & $0(3)$ & $9.26 \pm 0.06$ \\
\hline 27 & $0(90)$ & $0(2)$ & $0(1: 20)$ & $0(3)$ & $9.39 \pm 0.37$ \\
\hline 28 & $0(90)$ & $0(2)$ & $0(1: 20)$ & $0(3)$ & $9.29 \pm 0.04$ \\
\hline 29 & $0(90)$ & $0(2)$ & $0(1: 20)$ & $0(3)$ & $9.22 \pm 0.03$ \\
\hline 30 & $0(90)$ & $0(2)$ & $0(1: 20)$ & $0(3)$ & $8.7 \pm 0.16$ \\
\hline
\end{tabular}

extraction yield did not change obviously by increasing the extraction temperature and water to raw material ratio. As shown in Figure 1(c), the extraction yield did not change significantly with the change of extraction temperature and extraction frequency. Response surface of extraction temperature and extraction frequency was relatively smooth, and the contour was relatively sparse. It was worth noting that the response surface of extraction time was relatively steep, and the contour lines were relatively dense, compared with those of water to raw material ratio and extraction frequency (Figures 1(d) and 1(e)), suggesting that extraction time was the main factor for the extraction yield of RLP.

According to the analysis by the Design Expert Software, the optimal extraction conditions were as follows: extraction temperature, $93^{\circ} \mathrm{C}$; extraction time, $2.8 \mathrm{~h}$; water to raw mate- rial ratio, 22; and extraction frequency, 3. Among the four extraction parameters, the extraction time was the most significant factor affecting polysaccharides yield; the extraction temperature, extraction frequency, and water to raw material ratio were not significant factors affecting yield within the test range used. The suitability of the model equation for predicting optimum response values was determined using the optimized condition to validate and predict the values of the responses using the model equation. Compared with the predicted value 9.56, a mean value of $9.61 \pm 0.08(n=3)$ was obtained from the experiments. This result validated the adequacy of the RSM model for describing the extraction process.

3.2. Isolation and Purification. The crude RLP was obtained and loaded onto a DEAE-cellulose column equilibrated with 
TABLE 2: ANOVA for response surface quadratic model.

\begin{tabular}{|c|c|c|c|c|c|}
\hline Variables & $\begin{array}{l}\text { Sun of } \\
\text { squares }\end{array}$ & $\mathrm{DF}$ & $\begin{array}{c}\text { Mean } \\
\text { square }\end{array}$ & $F$ value & $P$ value \\
\hline$X_{1}$ & 0.2646 & 1 & 0.2646 & 3.3678 & $0.0864^{\mathrm{b}}$ \\
\hline$X_{2}$ & 0.6801 & 1 & 0.6800 & 8.6558 & $0.0101^{\mathrm{a}}$ \\
\hline$X_{3}$ & 0.0204 & 1 & 0.0204 & 0.2599 & $0.6176^{\mathrm{b}}$ \\
\hline$X_{4}$ & 0.1504 & 1 & 0.1504 & 1.9145 & $0.1867^{\mathrm{b}}$ \\
\hline$X_{1} X_{2}$ & 0.0256 & 1 & 0.0256 & 0.3258 & $0.5766^{\mathrm{b}}$ \\
\hline$X_{1} X_{3}$ & 0.81 & 1 & 0.81 & 10.3096 & $0.0058^{\mathrm{a}}$ \\
\hline$X_{1} X_{4}$ & 0.007225 & 1 & 0.0072 & 0.09196 & $0.7659^{\mathrm{b}}$ \\
\hline$X_{2} X_{3}$ & 1.3225 & 1 & 1.3225 & 16.8326 & $0.0009^{\mathrm{a}}$ \\
\hline$X_{2} X_{4}$ & 0.3306 & 1 & 0.3306 & 4.2082 & $0.0581^{\mathrm{b}}$ \\
\hline$X_{3} X_{4}$ & 1.3806 & 1 & 1.3806 & 17.5724 & $0.0008^{\mathrm{a}}$ \\
\hline$X_{1}^{2}$ & 0.9240 & 1 & 0.9240 & 11.7606 & $0.0037^{\mathrm{a}}$ \\
\hline$X_{2}^{2}$ & 0.1384 & 1 & 0.1384 & 1.7619 & $0.2042^{\mathrm{b}}$ \\
\hline$X_{3}^{2}$ & 3.7507 & 1 & 3.7507 & 47.7390 & $<0.0001^{\mathrm{a}}$ \\
\hline$X_{4}^{2}$ & 4.3566 & 1 & 4.3566 & 55.4506 & $<0.0001^{\mathrm{a}}$ \\
\hline Model & 12.3418 & 14 & 0.8816 & 11.2204 & $<0.0001^{\mathrm{a}}$ \\
\hline Residual & 1.1785 & 15 & 0.0786 & & \\
\hline Lack of fit & 0.8548 & 10 & 0.0855 & 1.3202 & 0.4001 \\
\hline Pure error & 0.3237 & 5 & 0.0647 & & \\
\hline Cor total & 13.5204 & 29 & & & \\
\hline \multicolumn{6}{|l|}{$R^{2}=0.9128$} \\
\hline \multicolumn{6}{|l|}{$R_{\mathrm{adj}}^{2}=0.8315$} \\
\hline C.V. $\%=3.3429$ & & & & & \\
\hline
\end{tabular}

${ }^{\mathrm{a}}$ Significance $(P<0.05){ }^{\mathrm{b}}{ }^{\mathrm{n}}$ nonsignificance $(P>0.05)$.

a linear $\mathrm{NaCl}$ gradient. Three independent elution peaks, RLP-1, RLP-2, and RLP-3 (Figure 2(a)) were detected by the phenol-sulfuric acid method. The three fractions were collected for the subsequent purification with Sepharose CL-4B column and presented single peaks RLP-1a, RLP-2a, and RLP-3a, respectively (Figure 2(b)). Then, RLP-1a, RLP$2 a$, and RLP-3a were collected for further structural characterization and antioxidant activity assays.

3.3. Molecular Weight of RLPs. Based on the distribution of molecule weight as determined by HPGPC analysis, RLP1a, RLP-2a, and RLP-3a fractions produced a single symmetrical and narrow peak (Figure 3), indicating they were homogeneous polysaccharides. According to the calibration curve, the average molecular weights of RLP-1a, RLP-2a, and RLP3a were estimated to be about $9004 \mathrm{Da}, 8761 \mathrm{Da}$, and $7571 \mathrm{Da}$, respectively. In previous studies, Yu et al. [1] obtained two major fractions which were $21.5 \mathrm{kDa}$ and $16.1 \mathrm{kDa}$. Zhan et al. [2] obtained an acid polysaccharide with the $\mathrm{Mw}$ of $137.1 \mathrm{kDa}$ from $R$. Laevigatae fruits. But the $\mathrm{Mw}$ of the polysaccharides that we obtained from $R$. Laevigatae fruits were less than $10 \mathrm{kDa}$, far less than the previous studies. Previous studies have reported that the large molecular weight of polysaccharides (over $10 \mathrm{kDa}$ ) led to poor water solubility and unfavorable for the absorption into the body, reduced the biological activities, and possibly limited the applications of polysaccharides, whereas the low molecular weight polysaccharides less than $10 \mathrm{kDa}$ had relatively higher activities to human health $[18,19]$.

3.4. Structural Analyses of RLPs. The monosaccharide compositions of RLP-1a, RLP-2a, and RLP-3a were identified by comparing the retention time with external standards by GC-MS analysis as shown in Table 3. The monosaccharide compositions showed that RLP-1a contained five different monosaccharides including ribose, arabinose, xylose, glucose, and galactose with the molar ratio of $3.14: 8.21: 1: 1.37: 4.90$, whereas RLP-2a consisted of four different monosaccharides including ribose, mannose, glucose, and galactose with the molar ratio of $1.70: 1: 93.59: 2.73$, and RLP-3a contained six different monosaccharides including ribose, arabinose, xylose, mannose, glucose, and galactose with a molar ratio of $6.04: 26.51: 2.05: 1: 3.17: 31.77$.

RLP-1a, RLP-2a, and RLP-3a showed no absorbance peaks at 280 and $260 \mathrm{~nm}$ by UV scanning, revealing the absence of protein and nucleic acid in polysaccharides (Figure 4(a)). FT-IR spectroscopy is a suitable technique for the identification of characteristic organic groups in the polysaccharides. As shown in Figure 4(b), the different absorption bands of the FT-IR analysis were assigned as previously reported $[25,29]$. The broad stretching peak at $3400 \mathrm{~cm}^{-1}$ was ascribed to the hydroxyl groups with stretching vibration. The weak absorption peaks at $2935 \mathrm{~cm}^{-1}$ and $2939 \mathrm{~cm}^{-1}$ were characteristic of C-H stretching vibration, and these bands above were characteristic absorption peaks of polysaccharides. The characteristic absorption band near $883 \mathrm{~cm}^{-1}$ indicated that RLP-1a, RLP-2a, and RLP-3a contained $\beta$-type glycosidic bond [30]. Moreover, near $1715 \mathrm{~cm}^{-1}$ without absorption further explained that no uronic acids existed in polysaccharides [31].

NMR spectra were employed to further confirm the obtained structure data and provide more detailed polysaccharide structural information. Generally, it is believed that there are several kinds of monosaccharides when there are several proton resonance signals in the spectrum $\delta 4.0$ $6.0 \mathrm{ppm}$ in the ${ }^{1} \mathrm{H}-\mathrm{NMR}$ spectrum. In ${ }^{1} \mathrm{H}-\mathrm{NMR}$, RLP-1a had six signals at $\delta 4.42, \delta 4.56, \delta 4.61, \delta 5.01, \delta 5.11$, and $\delta$ $5.15 \mathrm{ppm}$ (Table 4 ), indicating that there were both $\alpha$-linkage and $\beta$-linkage in the glycosidic bonds of RLP-1a. There was no proton signal at $\delta 5.4 \mathrm{ppm}$, indicating that RLP-1a was composed of glucopyranose [25]. Besides, an independent methyl signal was observed at $\delta 1.24 \mathrm{ppm}$. It was assigned to Rhap [32].

In the ${ }^{13} \mathrm{C}-\mathrm{NMR}$ spectrum of RLP-1a (Table 4$), \delta 107.46$, $\delta 106.87, \delta 102.48, \delta 101.68, \delta 96.06$, and $\delta 91.99 \mathrm{ppm}$ were shown in $\delta 90-110 \mathrm{ppm}$ hetero-carbon region, indicating that there were at least six monosaccharide residues in RLP-1a. Generally, for pyranose residue attended in glycosidic linkage, the chemical shift of anomeric carbon was in the range of $\delta 100-106 \mathrm{ppm}$ in $\beta$ configuration and $\delta 93-100 \mathrm{ppm}$ in $\alpha$ configuration [31]. When present as a reducing terminal, the movement to the high field was observed [32]. According 

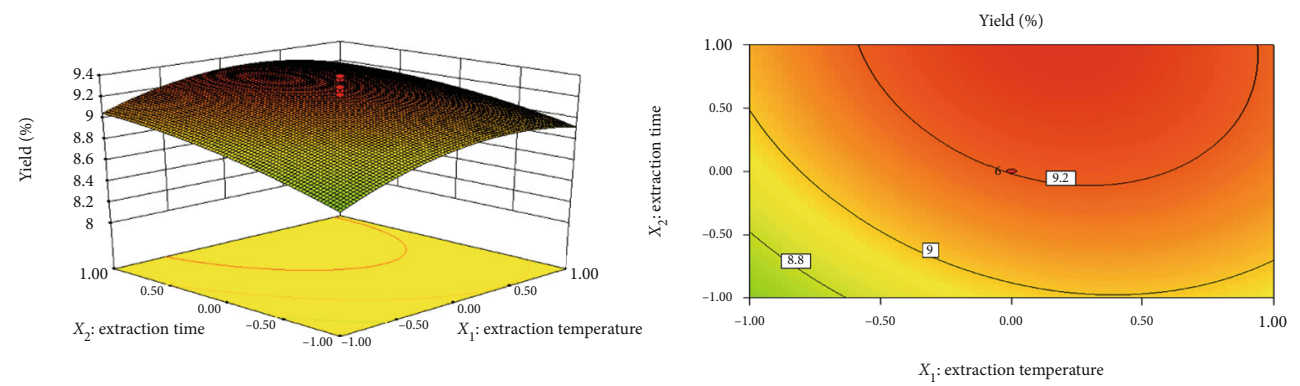

(a)
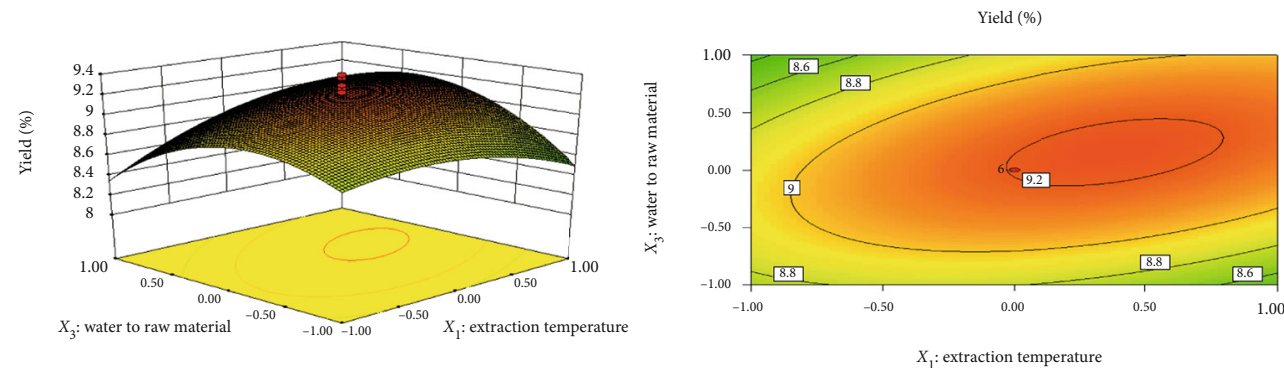

(b)
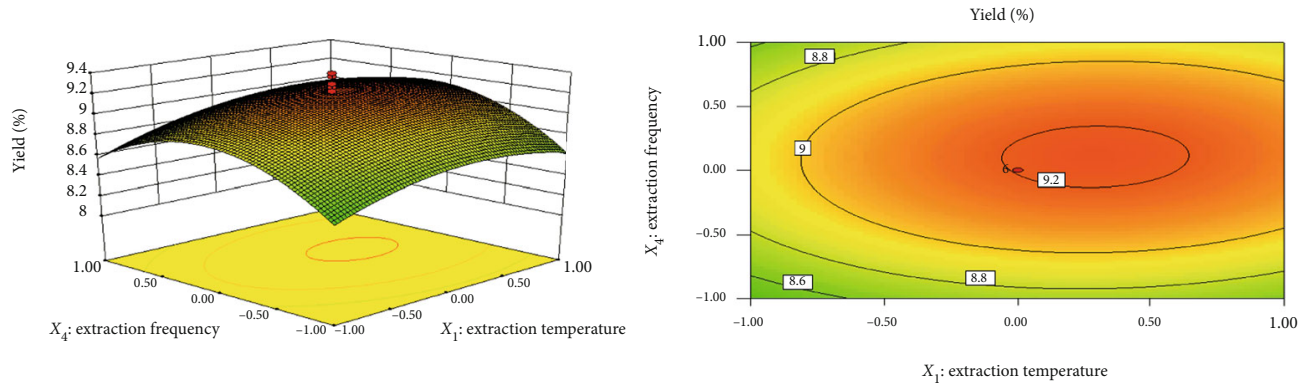

(c)
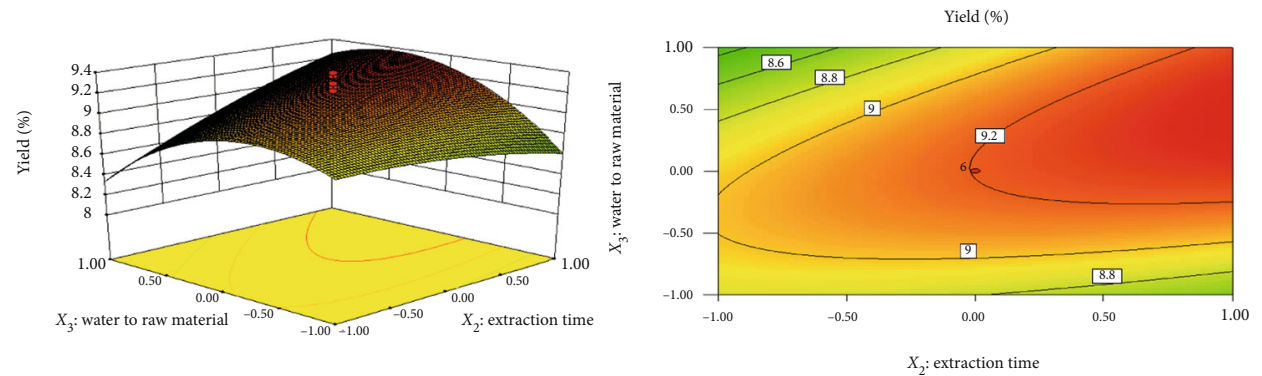

(d)
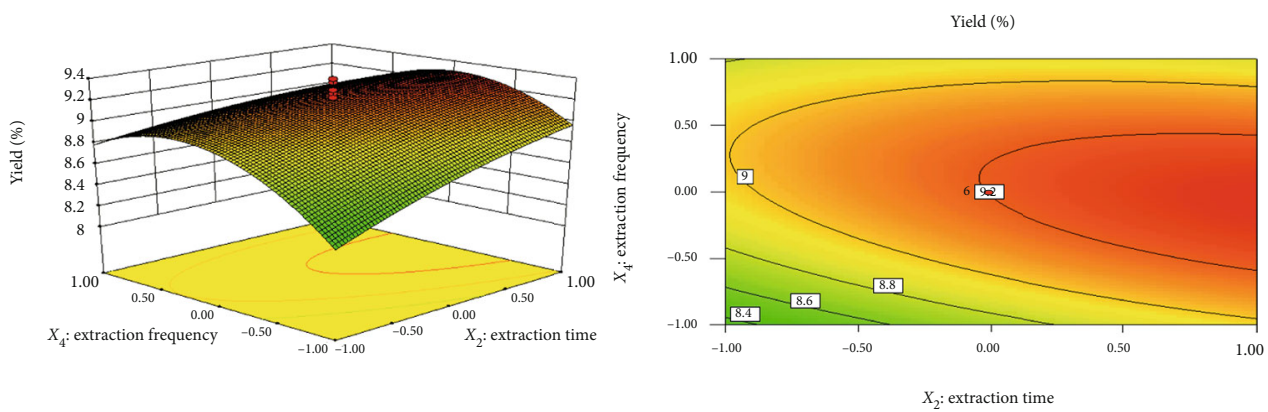

(e)

FIgURe 1: Continued. 

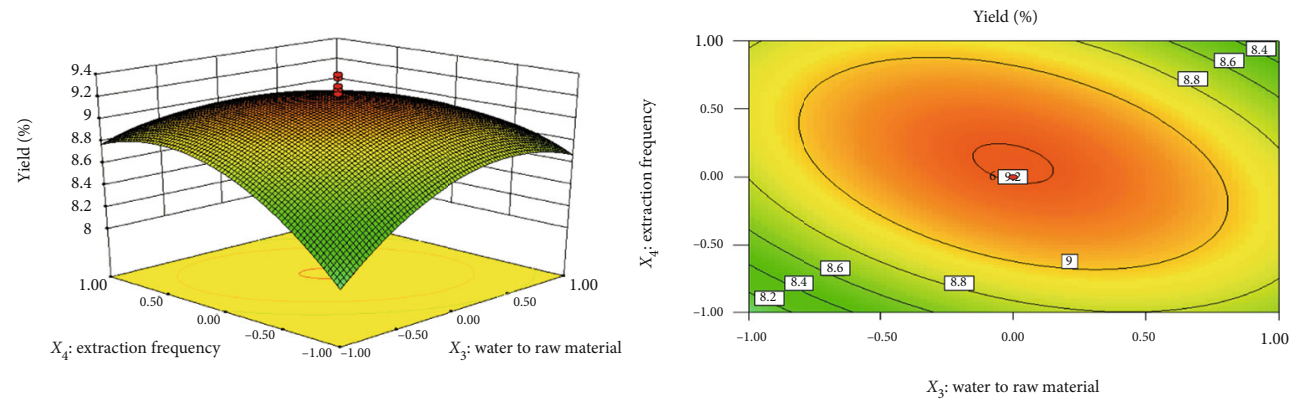

(f)

FIGURE 1: The response surface plots and contour plots of the interaction effects of four different variables $\left(X_{1}\right.$ : extraction temperature, ${ }^{\circ} \mathrm{C}$; $X_{2}$ : extraction time, $\mathrm{h} ; X_{3}$ : ratio of water to raw material, $\mathrm{mL} / \mathrm{g} ; X_{4}$ : extraction frequency) on the response yield of RLP.

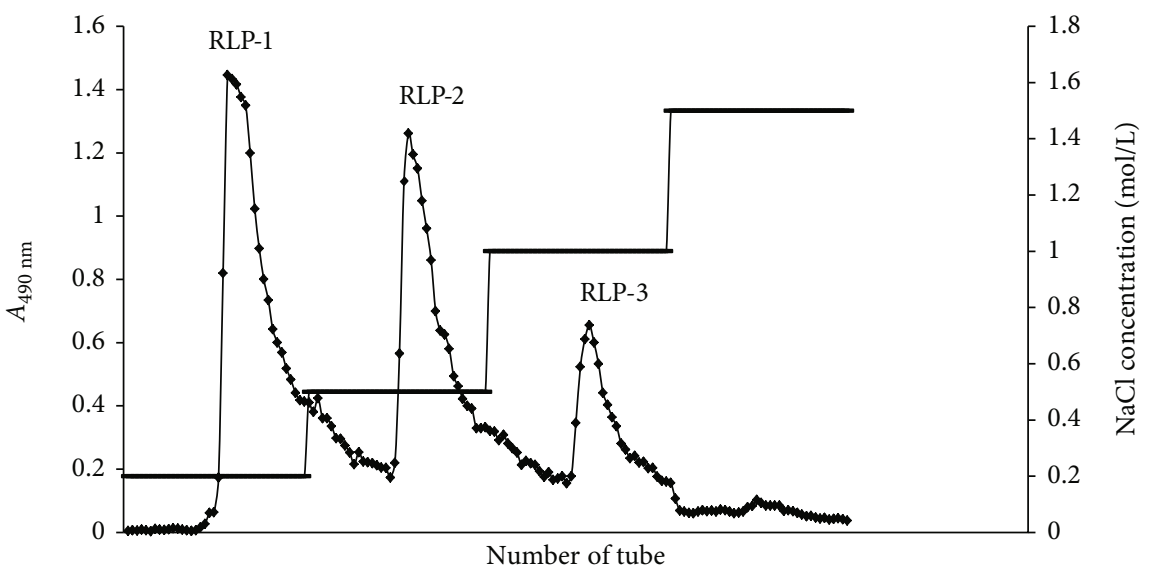

(a)
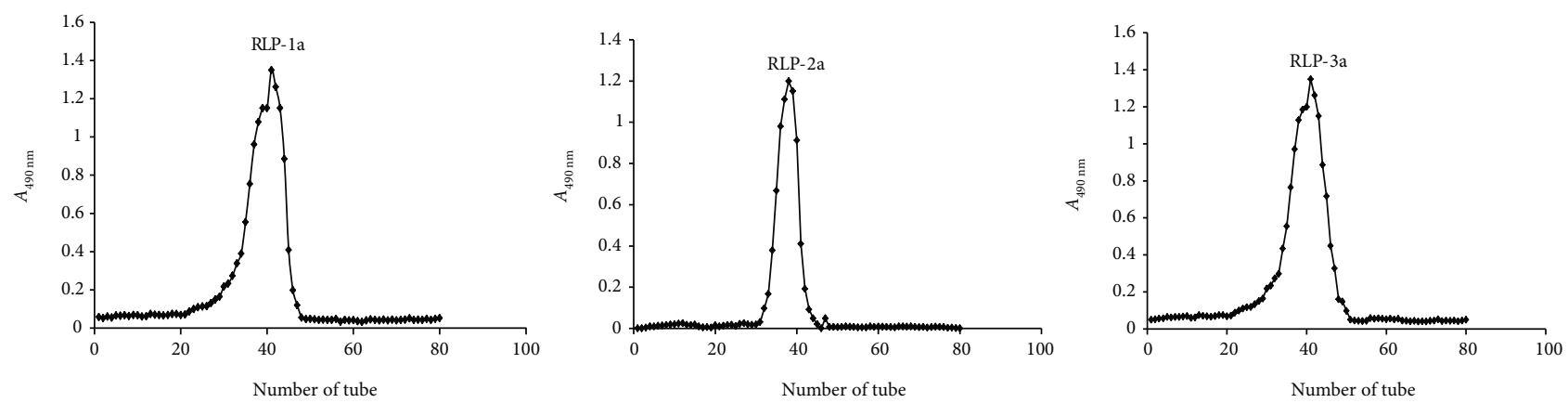

(b)

Figure 2: Elution curve of RLP on DEAE-cellulose DE-52 column (a) and elution curve of RLP-1, RLP-2, and RLP-3 on Sepharose CL-4B column (b).

to the analysis of monosaccharide composition, RLP-1a contained five monosaccharides, which were ribose, arabinose, xylose, glucose, and galactose. It suggested that $\delta$ $107.46 \mathrm{ppm}$ signals were assigned to $\mathrm{C}-1$ of the $\alpha$-L-Araf. And the analysis of the anomeric region of the spectrum showed that the signals at $\delta 106.87, \delta 102.48, \delta 101.68$, and $\delta 96.06 \mathrm{ppm}$ were attributed to $\mathrm{C}-1$ of the $\alpha$-D-Glcp, $\beta$-DGal $p, \beta$-Xyl $p$, and $\alpha$-L-Rha $p$ units, respectively $[33,34]$. The weak signal at $\delta 91.99 \mathrm{ppm}$ might be from $\alpha$-D-Glcp at the end of the chain [31]. The absence of signals from $\delta 120$ to 175 ppm suggested that RLP-1a contained no hexuronic acid, acetyl amino compounds, and carboxyl [34].

Chemical shift assignments for the ${ }^{13} \mathrm{C}-\mathrm{NMR}$ and ${ }^{1} \mathrm{H}$ NMR spectra of RLP-2a were showed in Table 4. Four single

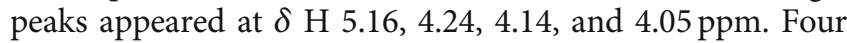
weak anomeric carbon signals of RLP-2a were detected, suggesting that four monosaccharides existed in each polysaccharide unit. 

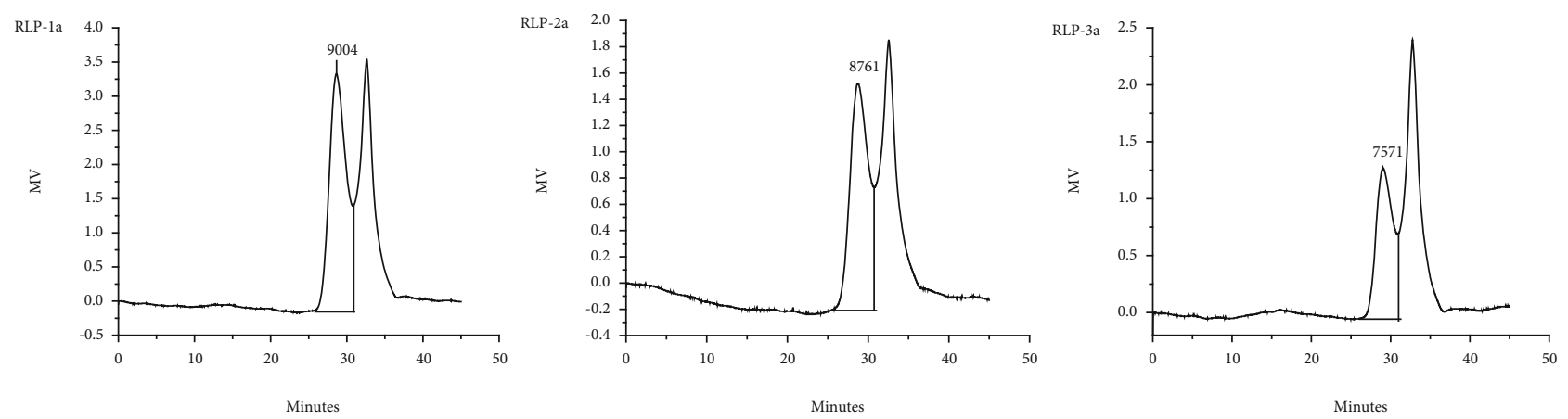

FIGURE 3: HPGPC chromatogram of low molecular weight soluble polysaccharides RLP-1a, RLP-2a, and RLP-3a from R. Laevigatae fruits.

TABLE 3: Monosaccharide composition of low molecular weight soluble polysaccharides RLP-1a, RLP-2a, and RLP-3a from R. Laevigatae fruits.

\begin{tabular}{lcccccc}
\hline \multirow{2}{*}{ Polysaccharides fractions } & & \multicolumn{3}{c}{ Monosaccharide composition (molecular ratio (\%)) } \\
& Rha & Ara & Xyl & Man & Glc & Gal \\
\hline RLP-1a & $3.14 \pm 0.20$ & $8.21 \pm 0.09$ & $1.0 \pm 0.02$ & - & $1.37 \pm 0.44$ & $4.9 \pm 0.13$ \\
RLP-2a & $1.70 \pm 0.05$ & - & - & $1.0 \pm 0.04$ & $93.59 \pm 0.1$ & $2.73 \pm 0.10$ \\
RLP-3a & $6.04 \pm 0.06$ & $26.51 \pm 0.08$ & $2.05 \pm 0.03$ & $1.0 \pm 0.02$ & $3.17 \pm 0.07$ & $31.77 \pm 0.09$ \\
\hline
\end{tabular}

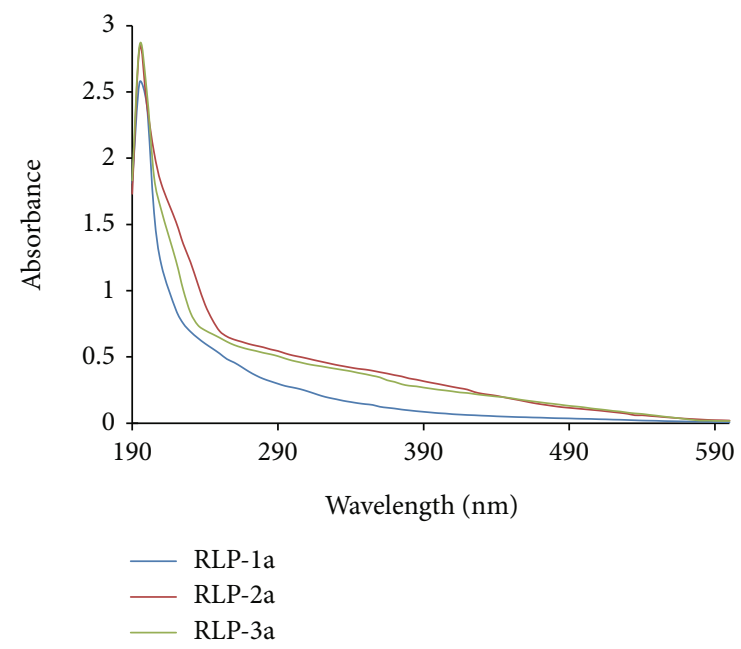

(a)
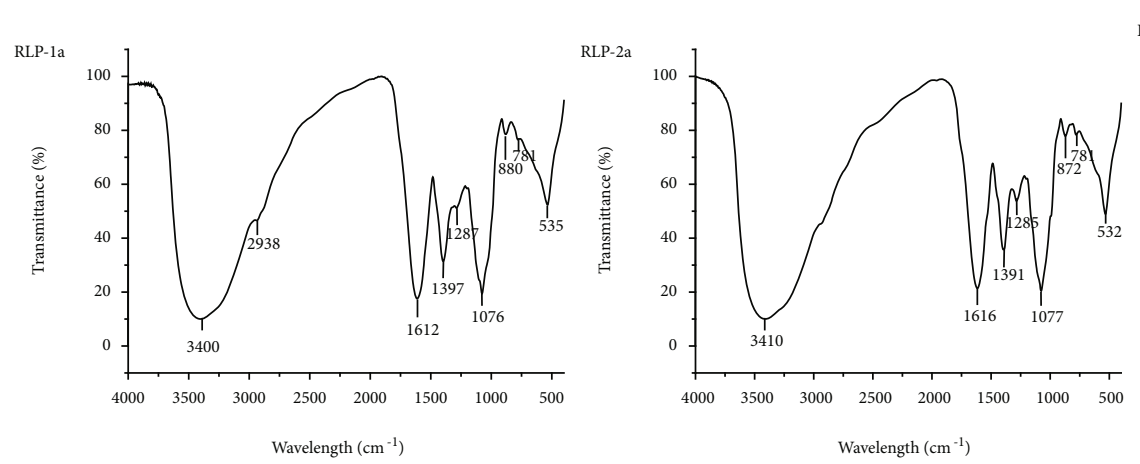

(b)

FIGURE 4: UV spectrophotometry analysis (a) and FT-IR spectrophotometry analysis (b) of the purity of low molecular weight soluble polysaccharides RLP-1a, RLP-2a, and RLP-3a from $R$. Laevigatae fruits. 
TABLE 4: Chemical shifts of resonances in the ${ }^{1} \mathrm{H}$ and ${ }^{13} \mathrm{C}$ spectra of RLP-1a, RLP-2a, and RLP-3a (ppm).

\begin{tabular}{|c|c|c|c|c|c|c|c|}
\hline Polysaccharide fractions & Residues & $\mathrm{C} 1 / \mathrm{H} 1$ & $\mathrm{C} 2 / \mathrm{H} 2$ & $\mathrm{C} 3 / \mathrm{H} 3$ & $\mathrm{C} 4 / \mathrm{H} 4$ & $\mathrm{C} 5 / \mathrm{H} 5$ & $\mathrm{C} 6 / \mathrm{H} 6$ \\
\hline \multirow{6}{*}{ RLP-1a } & $(1 \rightarrow 6)-\alpha-\mathrm{D}-\mathrm{Gl} c p$ & $106.87 / 5.11$ & $76.64 / 3.88$ & $75.91 / 3.16$ & $73.27 / 3.16$ & $72.82 / 3.73$ & $69.56 / 3.31$ \\
\hline & $(1 \rightarrow 4)-\alpha$-L-Araf $p$ & $107.46 / 5.01$ & $76.52 / 3.39$ & $77.76 / 3.73$ & $81.34 / 4.06$ & $75.91 / 3.32$ & $69.56 / 4.06$ \\
\hline & $(1 \rightarrow)-\alpha$-D-Glcp terminal & $91.99 / 5.15$ & $76.64 / 3.16$ & $76.20 / 4.06$ & $75.76 / 3.31$ & $69.50 / 3.31$ & $60.75 / 3.73$ \\
\hline & $(1 \rightarrow 3,4)-\beta$-D-Xyl $p$ & $101.68 / 4.61$ & $75.76 / 3.39$ & $82.03 / 3.73$ & $71.42 / 3.16$ & $60.75 / 3.64$ & $-/-$ \\
\hline & $(1 \rightarrow 6)-\beta-\mathrm{D}-\mathrm{Gal} p$ & $102.48 / 4.42$ & $69.57 / 3.31$ & $72.72 / 3.73$ & $71.42 / 3.80$ & $60.75 / 4.08$ & $69.15 / 3.31$ \\
\hline & $(1 \rightarrow 3)-\beta-\mathrm{L}-\mathrm{Rha}$ & $96.06 / 4.56$ & $79.73 / 4.21$ & $81.34 / 4.06$ & $75.76 / 3.32$ & $69.56 / 4.06$ & $60.75 / 3.31$ \\
\hline \multirow{4}{*}{ RLP-2a } & $(1 \rightarrow 4)-\alpha-\mathrm{D}-\mathrm{Gl} c p$ & $109.30 / 5.16$ & $75.95 / 3.96$ & $75.81 / 3.31$ & $89.37 / 3.96$ & $70.09 / 3.45$ & $60.92 / 3.74$ \\
\hline & $(1 \rightarrow 5)-\beta$-D-Man $p$ & $104.55 / 4.14$ & $75.91 / 3.38$ & $89.37 / 3.45$ & $75.81 / 3.69$ & $81.43 / 4.15$ & $61.12 / 3.96$ \\
\hline & $(1 \rightarrow 4)-\beta-\mathrm{D}-\mathrm{Gal} p$ & $103.43 / 4.24$ & $76.64 / 3.88$ & $76.20 / 4.06$ & $81.43 / 4.14$ & $75.81 / 3.41$ & $61.12 / 3.64$ \\
\hline & $(1 \rightarrow 2)-\beta$-L-Rhap & $100.52 / 4.05$ & $81.43 / 4.14$ & $75.95 / 3.85$ & $70.09 / 3.74$ & $68.58 / 3.77$ & $60.92 / 3.77$ \\
\hline \multirow{6}{*}{ RLP-3a } & $(1 \rightarrow 4,6)-\alpha-\mathrm{L}-\mathrm{Araf} p$ & $109.16 / 5.17$ & $75.71 / 3.42$ & $72.27 / 3.42$ & $81.66 / 4.06$ & $73.28 / 3.4$ & $69.51 / 3.62$ \\
\hline & $(1 \rightarrow 5)-\alpha-\mathrm{D}-\mathrm{Gl} c p$ & $107.39 / 5.01$ & $72.27 / 3.93$ & $75.71 / 3.42$ & $68.78 / 3.93$ & $81.20 / 4.06$ & $60.97 / 3.75$ \\
\hline & $(1 \rightarrow 6)-\alpha-\mathrm{D}-\mathrm{Gal} p$ & $106.96 / 5.08$ & $66.09 / 3.81$ & $75.71 / 4.06$ & $83.36 / 3.86$ & $61.09 / 3.65$ & $68.78 / 3.93$ \\
\hline & $(1 \rightarrow 6)-\beta-\mathrm{D}-\mathrm{Man} p$ & $102.94 / 4.43$ & $68.78 / 3.86$ & $81.20 / 4.14$ & $61.09 / 3.75$ & $60.97 / 3.60$ & $66.09 / 3.81$ \\
\hline & $(1 \rightarrow 4)-\beta$-D-Xyl $p$ & $100.82 / 4.66$ & $72.27 / 3.60$ & $68.78 / 3.93$ & $83.36 / 3.93$ & $60.75 / 4.08$ & $-1-$ \\
\hline & $(1 \rightarrow 2)-\beta$-L-Rha $p$ & $99.31 / 4.93$ & $81.66 / 4.14$ & $69.52 / 3.31$ & $75.71 / 3.42$ & $66.09 / 3.81$ & $61.09 / 3.65$ \\
\hline
\end{tabular}

Chemical shift assignments for the ${ }^{13} \mathrm{C}-\mathrm{NMR}$ and ${ }^{1} \mathrm{H}$ NMR spectra of RLP-3a were showed in Table 4 . In $1 \mathrm{H}-$ NMR spectrum, six single peaks appeared at $\delta \mathrm{H} 5.17,5.08$, $5.01,4.93,4.66$, and 4.43 ppm, indicating that RLP-3a contained both $\alpha$ - and $\beta$-anomeric configurations. Six anomeric carbon signals at $\delta \mathrm{C} 109.16,107.39,106.96,102.94,100.82$, and $99.31 \mathrm{ppm}$ appeared in ${ }^{13} \mathrm{C}$-NMR spectrum, indicating that six monosaccharides existed in one unit. The signal $\delta \mathrm{H} / \delta \mathrm{C}(1.15 / 16.45)$ corresponded to the $-\mathrm{CH}_{3}$ groups of Rhap residues [35].

Scanning electron microscopy (SEM) can be used to determine the surface, the internal morphology, and the pore characteristics of polysaccharides [36]. To evaluate the differences in the surface morphological structure between RLP1a, RLP-2a, and RLP-3a, SEM was used to observe the microscopic appearances of RLP-1a, RLP-2a, and RLP-3a under 1000-fold magnification. RLP-1a had a sheet-like structure with a smooth and flat surface (Figure 5(a)), and RLP-2a was also flaky and smooth with more debris (Figure 5(b)). In contrast, the RLP-3a was present in smooth globular particles (Figure 5(c)). The microscopic morphology of the surface of the RLP-1a, RLP-2a, and RLP-3a was significantly different. The topology of the polysaccharides might be according to their different molecular arrangements [36, 37].

3.5. In Vitro Antioxidant Activity. The antioxidant activities of compounds are attributed to various reactions and mechanisms, such as radical scavenging, reductive capacity, prevention of chain initiation, and binding of transition metal ion catalysts [38]. In this work, the scavenging effects of RLP-1a, RLP-2a, and RLP-3a on hydroxyl, DPPH, and superoxide radicals were analyzed.

Hydroxyl free radical is the most active oxygen free radical, which causes various diseases including diabetes and is an important factor of oxidative damage [3]. As shown in Figure $6(\mathrm{a})$, the scavenging activity of RLP-1a, RLP-2a, and
RLP-3a was concentration dependent and lower than that of ascorbic acid at the test dosage range. When the concentration was $1.0 \mathrm{mg} / \mathrm{mL}$, the scavenging hydroxyl free radical value of RLP-3a reached $72.24 \pm 1.98 \%, 11.21 \%$ higher than that of RLP-1a $(P<0.01)$, and $31.79 \%$ higher than that of RLP-2a $(P<0.01)$, demonstrating that RLP-3a had the highest potential scavenging effect on superoxide radicals.

$\mathrm{DPPH}$, as a stable free radical, is a fast, convenient, and sensitive substance to evaluate the antioxidant activity in vitro [39]. As shown in Figure 6(b), the DPPH radical scavenging rates of RLP-1a, RLP-2a, and RLP-3a were concentration dependent and lower than that of ascorbic acid at the test dosage range. In the test dosage range, RLP-3a showed superior scavenging activity of DPPH radical compared with RLP-1a and RLP-2a. At $1.0 \mathrm{mg} / \mathrm{mL}$, the scavenging rates of RLP-1a, RLP-2a, and RLP-3a reached $72.48 \pm 2.19 \%$, $38.13 \pm 2.46 \%$, and $83.46 \pm 2.32 \%$, respectively.

Superoxide anion radicals are active and have strong oxidation and toxicity. They are the first free radicals produced by oxygen in the body and easy to be converted into other active oxygen radicals, causing further oxidative damage to the body [40]. The scavenging effects of RLP-1a, RLP-2a, and RLP-3a on the superoxide radical were shown in Figure 6(c). The scavenging rates of RLP-1a, RLP-2a, RLP$3 \mathrm{a}$, and ascorbic acid against superoxide radicals were directly proportional to their concentrations. In the test dosage range, the scavenging activity of ascorbic acid against superoxide radicals was remarkably higher than those of RLP-1a, RLP-2a, and RLP-3a. The scavenging superoxide rate of RLP-3a reached $82.30 \pm 2.72 \%$, and that of RLP-1a reached $75.43 \pm 1.87 \%$, which was higher than that of RLP$2 \mathrm{a}(40.79 \pm 2.45 \%)$ at $1.0 \mathrm{mg} / \mathrm{mL}$, indicating that RLP-3a and RLP-1a had superior antioxidant activities.

3.6. Effect of RLP on Body Weight. Changes in the body weight and food intake of rats after 12 weeks in the four 




(a)

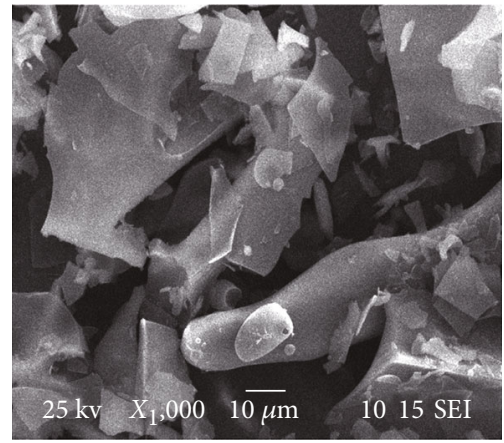

(b)

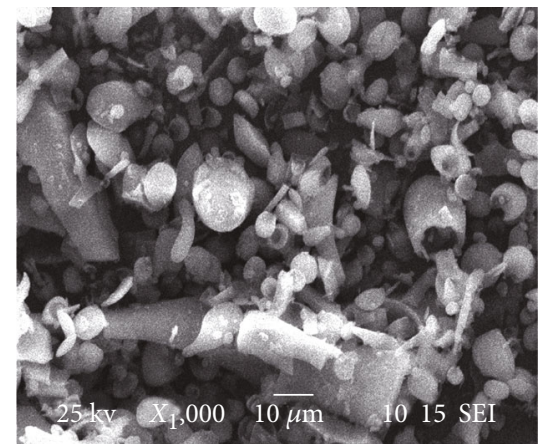

(c)

Figure 5: SEM images of (a) RLP-1a, (b) RLP-2a, and (c) RLP-2a.

groups (CN, HFD, HRLP, and LRLP) were shown in Table 5. There was no significant difference in body weight between the groups at the beginning of the experiment. However, at the end of the experiment, the weight gain of the HFD group was significantly higher than that of the $\mathrm{CN}$ group $(P<0.01)$. Compared with the HFD group, the HRLP and LRLP dosage groups had less weight gain $(P<0.01)$. The results indicated that RLP supplementation could inhibit the rat weight increase induced by high-fat diet.

3.7. Effect of RLP on Serum Lipid. The effects on serum lipid were exhibited in Figure 7. Compared with the CN group, the HFD group rats displayed a significant increase of TC, TG, LDL-C, and FFA levels, but the HDL-C levels significantly decreased $(P<0.05)$. With RLP intervention, LRLP and HRLP showed hypolipidemic activities. Compared with the HFD group, the HRLP group reduced TG $(P<0.05)$, TC $(P<0.05)$, FFA $(P<0.05)$, and LDL-C $(P<0.1)$ levels by $16.3 \%, 47.0 \%, 27.8 \%$, and $14.8 \%$, respectively, and the HDL-C levels significantly increased by $35.0 \%(P<0.05)$, indicating that RLP with higher dosage intervention had stronger hypolipidemic activities in rats, and the hypolipidemic activity of LRLP was weaker than that of HRLP.

High-fat diet induction reduced HDL-C levels and significantly increased TC, TG, and LDL levels, leading to lipid metabolism disorders. This might be due to the increased FFA accumulation in serum [41]. FFA could increase liver uptake resulting in excessive lipid accumulation, which was poisonous to liver and eventually caused hepatic steatosis [42]. After treatment with RLP, these levels of TC, TG, FFA, HDL-C, and LDL-C were distinctly relieved compared with HFD. Compared with the polysaccharides with high molecular, RLP showed more positive effects on reducing serum lipid levels in the high-dose group [1].

3.8. Antioxidant Status in the Liver. The effects of RLP on SOD, GSH-Px, and CAT activities in the livers of rats in different experimental groups were assessed in this study. As shown in Figure 8, the activities of SOD, GSH-Px, and CAT in the HFD group livers were significantly lower than those in the CN group $(P<0.01)$. Hyperlipidemia could reduce the activity of the antioxidant enzyme system, leading to peroxidation damage [43], whereas excessive free radicals could cause lipid peroxidation, further destroyed the lipid metabolism pathway in the liver and aggravated hyperlipidemia [44]. Compared with the HFD group, the SOD, GSH-Px, and CAT activity significantly increased in livers in the LRLP group with $28.4 \%, 27.5 \%$, and $19.6 \%(P<0.01)$ and in the HRLP group with $34.7 \%, 39.9 \%$, and $31.2 \%(P<0.01)$, indicating that HRLP had a significant effect on improving the antioxidant capacity of liver tissue. These results indicated that RLP could regulate the antioxidant enzyme system to resist the oxidative stress damage caused by the high-fat diet.

3.9. Functional Analysis of DEGs. GO is mainly to solve the confusion of the definition of the same genes in different databases and the confusion of the same genes in different species in the functional definition. GO has three ontologies, which describe the biological process (BP), cellular component (CC), and molecular function (MF) of genes. DEGs between HFD and $\mathrm{CN}$ groups were assigned to 391 biological processes, 103 cellular components, and 260 molecular functions. For DEGs between HRLP and HFD, 670 GO terms were significantly enriched, including 321 biological processes, 105 cellular components, and 244 molecular functions. For biological processes, the oxidation-reduction process and lipid metabolic process were differently regulated between the two groups (Figures 9(a) and 9(b)). Oxidation-reduction process and lipid metabolic process were mainly upregulated between HRLP and HFD and downregulated in the HFD vs. CN group.

3.10. KEGG Pathway Analysis of DEGs. Compared to the CN group, 305 pathways were obtained with HFD treatment. In contrast, compared with the HFD group, 290 important pathways were acquired with HRLP treatment, respectively, and the top 20 pathways were illustrated in (Figures 10(a) and $10(\mathrm{~b})$ ). Both HFD and HRLP regulated four pathways including peroxisome proliferator-activated receptor (PPAR) signaling pathway, fatty acid metabolism, steroid biosynthesis, and linoleic acid metabolism. We selected the PPAR signaling pathway to evaluate the mechanism by RLP-regulated HFD-induced metabolic dysfunction. For genes in the PPAR signaling pathway, compared with $\mathrm{CN}$ group, the expression of acyl coenzyme A oxidase 3 (ACOX3) $(P<0.05)$, which limited the fatty acid $\beta$-oxidation pathway significantly, 


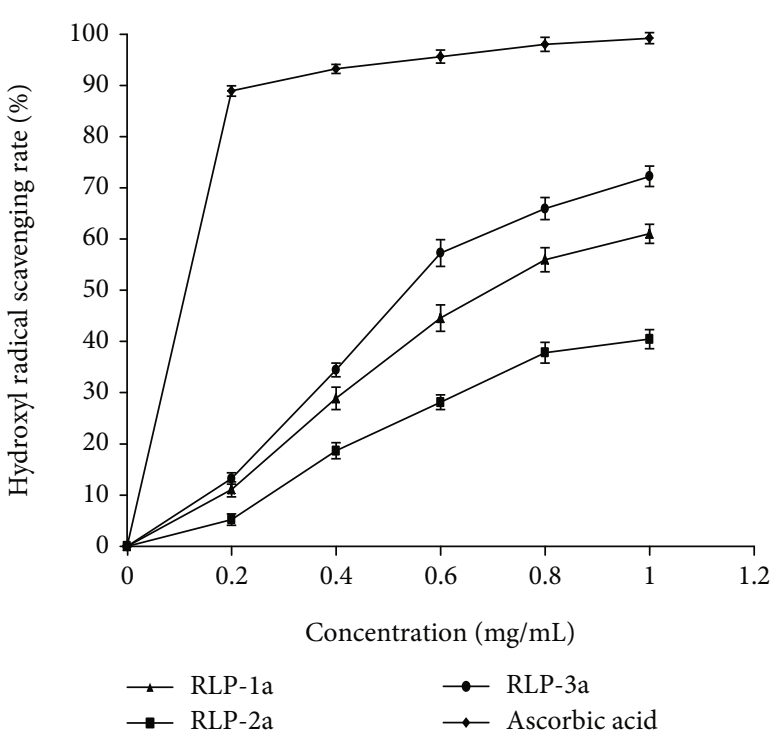

(a)

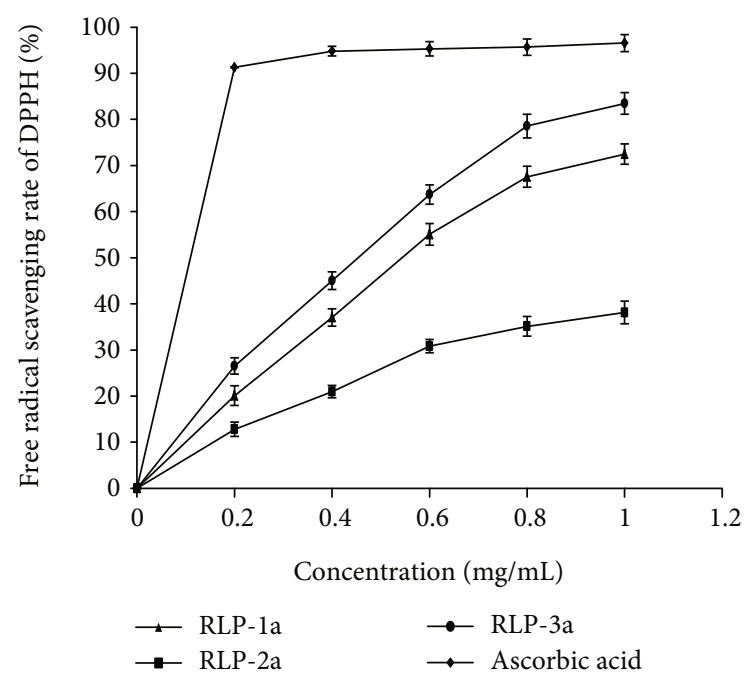

(b)

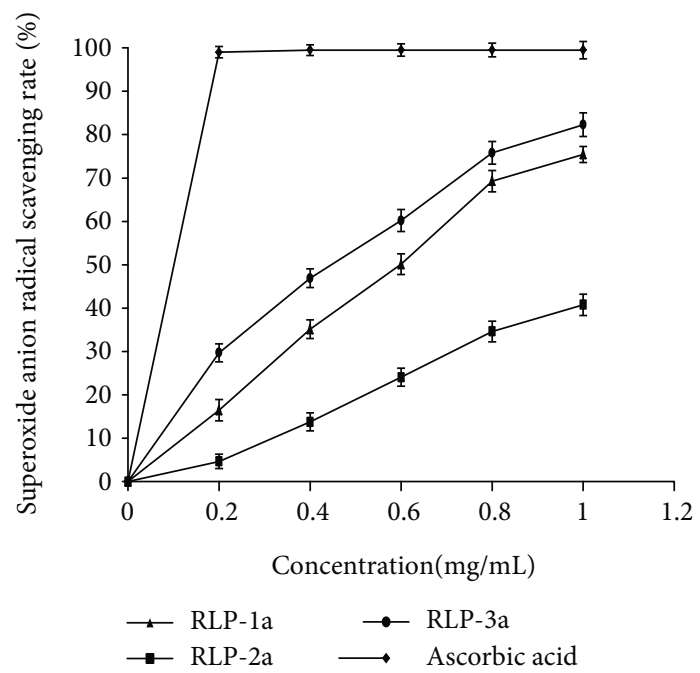

(c)

FIGURE 6: Effects of RLP-1a, RLP-2a, RLP-3a, and ascorbic acid in vitro antioxidant of (a) scavenging effects on hydroxyl radicals, (b) scavenging effects on DPPH, and (c) scavenging effects on superoxide anion radicals. The values were reported as the mean \pm SD. $(n=3$ for each group).

TABLE 5: Effects of RLP on body weight of different groups of rats.

\begin{tabular}{|c|c|c|c|}
\hline & \multicolumn{3}{|c|}{ Body weight (g) } \\
\hline & Initial & Final & Growth rate (\%) \\
\hline $\mathrm{CN}$ & $340.63 \pm 8.2$ & $503.66 \pm 10.3$ & 48.14 \\
\hline HFD & $337.75 .3 \pm 7.4$ & $654.66 \pm 11.2^{* *}$ & 93.80 \\
\hline HRLP & $352.38 \pm 6.0$ & $601.00 \pm 4.6^{\# \#}$ & 70.55 \\
\hline LRLP & $350.50 \pm 7.1$ & $616.76 \pm 7.6^{\# \#}$ & 76.00 \\
\hline
\end{tabular}

${ }^{* *} P<0.01$ : compared with the $\mathrm{CN}$ group. ${ }^{*} P<0.05$ : compared with HFD group. ${ }^{\# \#} P<0.01$ : compared with HFD group.

reduced in HFD group, and the expression of $A C O X 3$ in HRLP group was significantly higher than that in HFD group, indicating that RLP intervention could effectively reverse the downregulation of $A C O X 3$ caused by the high- fat diet. Fatty acyl-CoA imported to the mitochondria was desaturated to 2-trans-enoyl-CoAs by ACOX3 and further processed into $\beta$-oxidation [45]. Our results suggested that $A C O X 3$ expression was upregulated under RLP feeding conditions, promoted the decomposition of fatty acids, and reduced fat accumulation in the liver. Moreover, two significant down expressed key genes of lipid synthesis fatty acid desaturase 2 (FADS2) and stearoyl-coenzyme A desaturase $1(S C D-1)(P<0.05)$ were found between group HFD vs. $\mathrm{CN}$, which played a central role in the metabolism of longchain fatty acids. Under the intervention of RLP, the expressions of these genes were reversed.

FADS2 is a lipid biosynthetic protein. Linoleic acid is continuously converted into arachidonic acid in a pathway regulated by the FADS2 gene. The fatty acid dehydrogenase synthesized by FADS2 is a key enzyme in the biosynthesis 


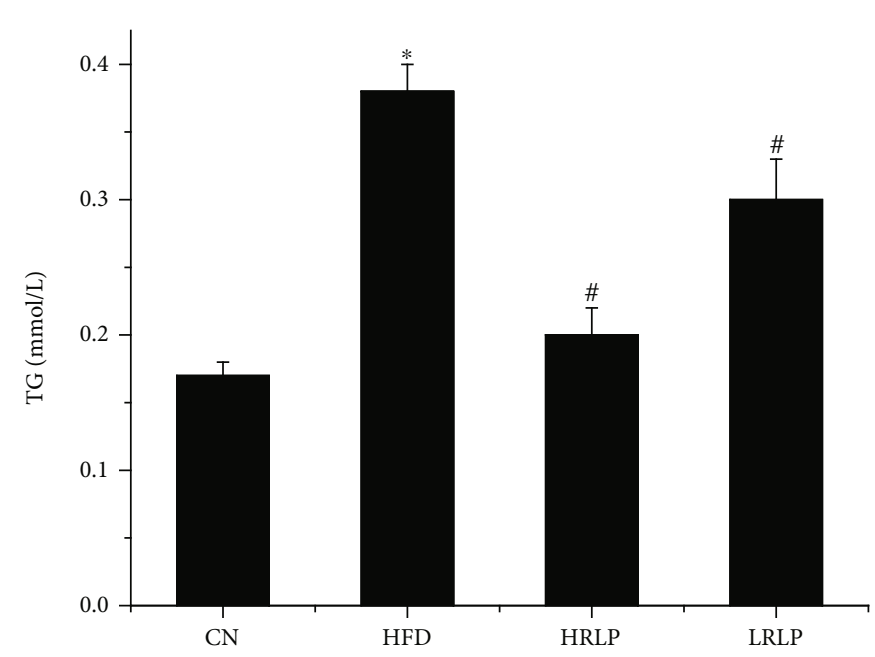

(a)

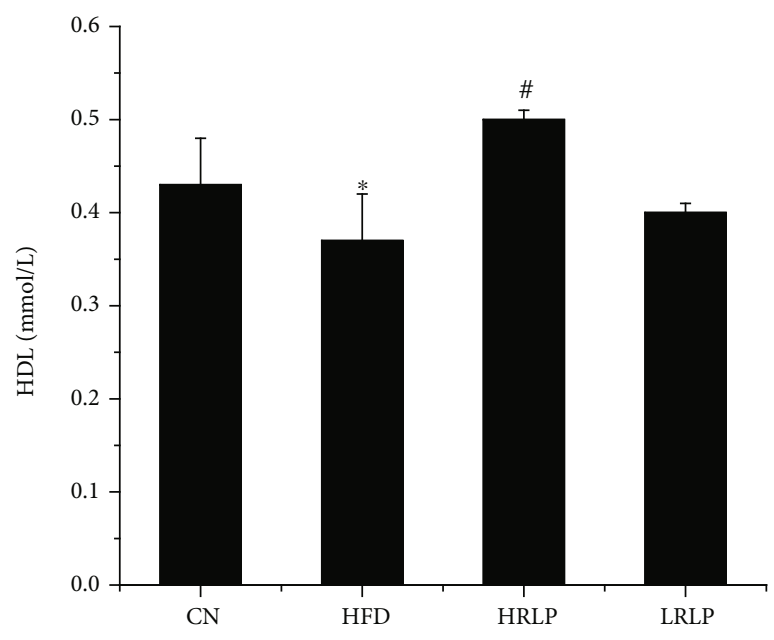

(c)

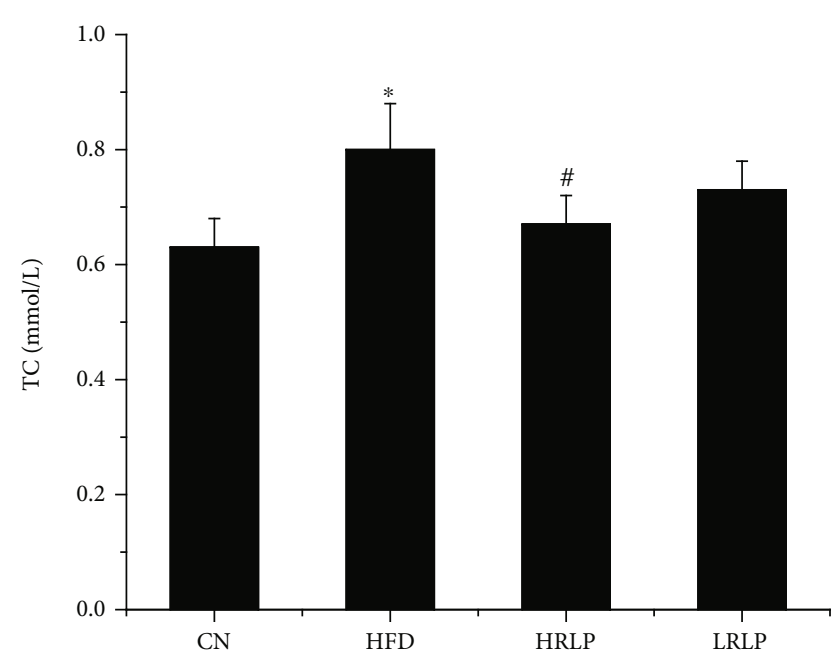

(b)

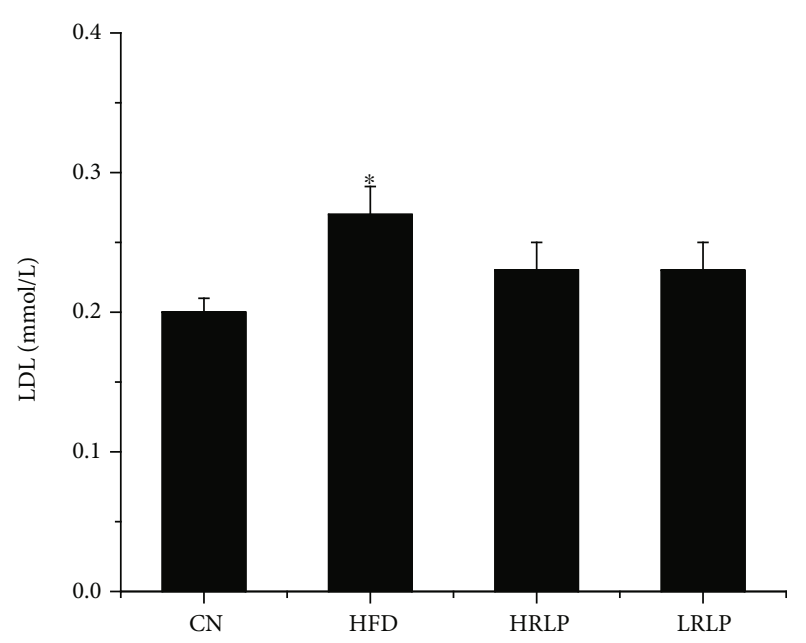

(d)



(e)

FIgURE 7: Effect of RLP on the serum lipids of HFD rats $(n=8, \mathrm{x} \pm \mathrm{s}) .{ }^{*} P<0.05$ vs. CN rats. ${ }^{*} P<0.05$ vs. HFD rats.

of unsaturated fatty acids, which is highly expressed in the liver. It has been reported that FADS2 has an inhibitory effect on hepatic lipid accumulation [46]. Our results revealed that
FADS2 expression was the highest under RLP feeding conditions. SCD-1 plays an important role in both hepatocyte apoptosis mediation and fatty acid metabolism. SCD-1 is an 




(a)

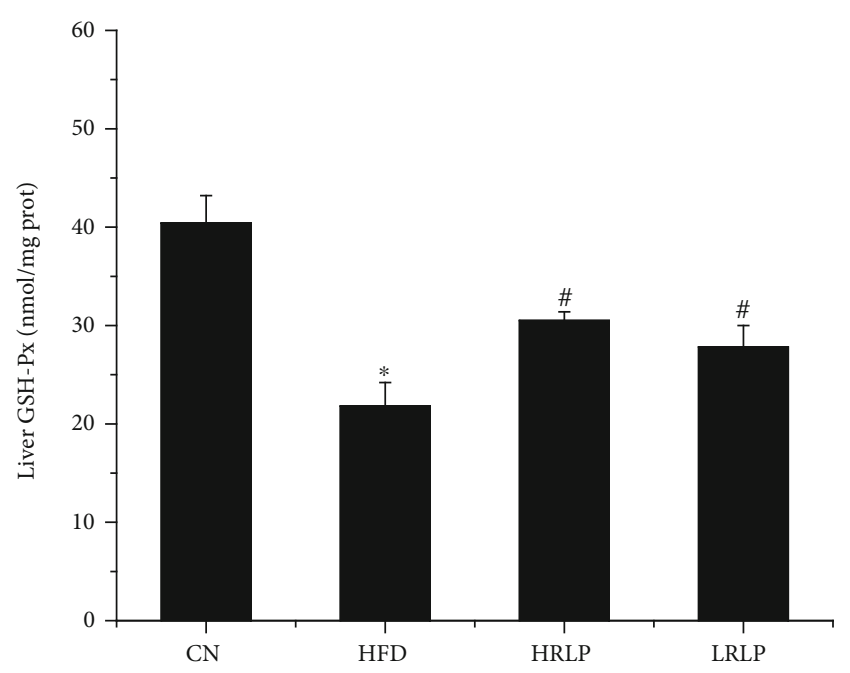

(b)

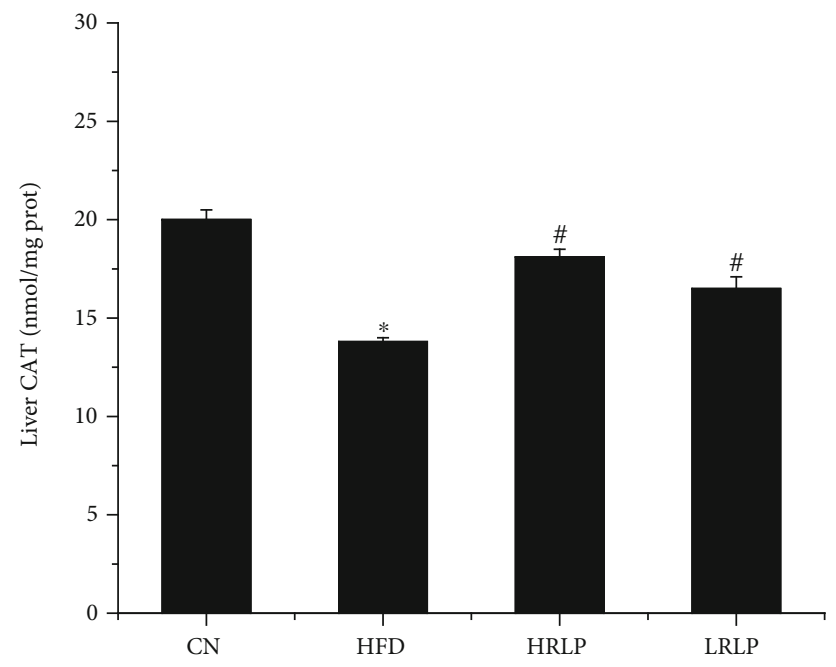

(c)

FIgURE 8: Effects of RLP on the activity of SOD, GSH-Px, and CAT in the liver of high-fat diet-fed rats $(n=8, \mathrm{x} \pm \mathrm{s}) .{ }^{*} P<0.01 \mathrm{vs} . \mathrm{CN}$ rats. ${ }^{\#} P<0.01$ vs. HFD rats.

endoplasmic reticulum enzyme, which catalyzes the ratelimiting step in monounsaturated fatty acid formation and is required to guard against dietary unsaturated fat deficiency [47]. Despite the abundance of monounsaturated fatty acids (MUFAs) in dietary fats, MUFAs are also synthesized de novo from saturated fatty acids by $S C D-1$ enzymes. $S C D-1$ deficient rats experience reduced MUFA synthesis, decreased HDL cholesterol levels, decreased lipid accumulation, and enhanced fatty acid oxidation [48-50]. Our data showed that $S C D-1$ was downexpressed by HFD feeding and increased by RLP intervention, indicating that nonalcoholic fatty liver caused by HFD led to decrease in SCD-1. After taking RLP, the expression level of $S C D-1$ increased, resulting in a large increase in HDL cholesterol and a lipid accumulation decrease in the liver of HFD rats.

mRNA expressions of $A C O X 3, F A D S 2$, and $S C D-1$ were genes involved in fatty acid metabolism and play an important role in the PPAR signaling pathway. It was noted that
RLP treatment at $800 \mathrm{mg} / \mathrm{kg}$ doses significantly promoted the expression of peroxisome proliferator-activated receptor alpha (PPARa) target genes $A C O X 3$ and increased the expression of lipid synthesis genes such as FADS2 and $S C D-1$ expression $(P<0.05)$. The RNA-Seq investigation was consistent with the results of the qRT-PCR analyses (Figures 11(a) and 11(b)).

\section{Conclusions}

Three novel low molecular weight polysaccharides RLP-1a, RLP-2a, and RLP-3a of $9004 \mathrm{Da}, 8761 \mathrm{Da}$, and $7571 \mathrm{Da}$, respectively, were purified from the $R$. Laevigatae fruits, which had 6, 4, and 6 types of glycosidic linkages, respectively. The present study demonstrated that these RLPs exhibited the distinct hypolipidemic and antioxidant effects in high-fat diet-induced rats. RLPs enhanced antioxidant enzyme activities, protected liver cells, improved serum lipid 


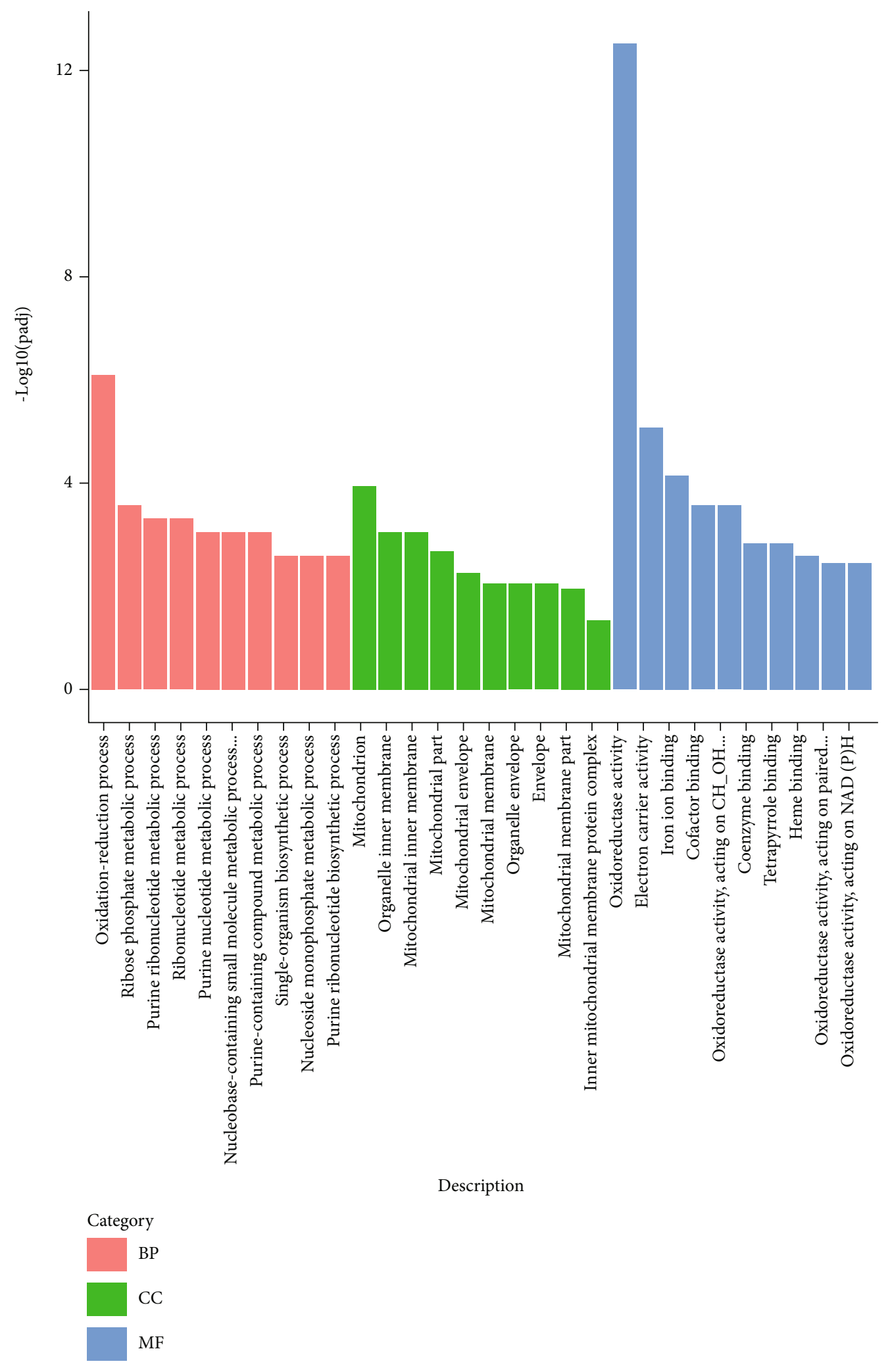

(a)

FIgURe 9: Continued. 


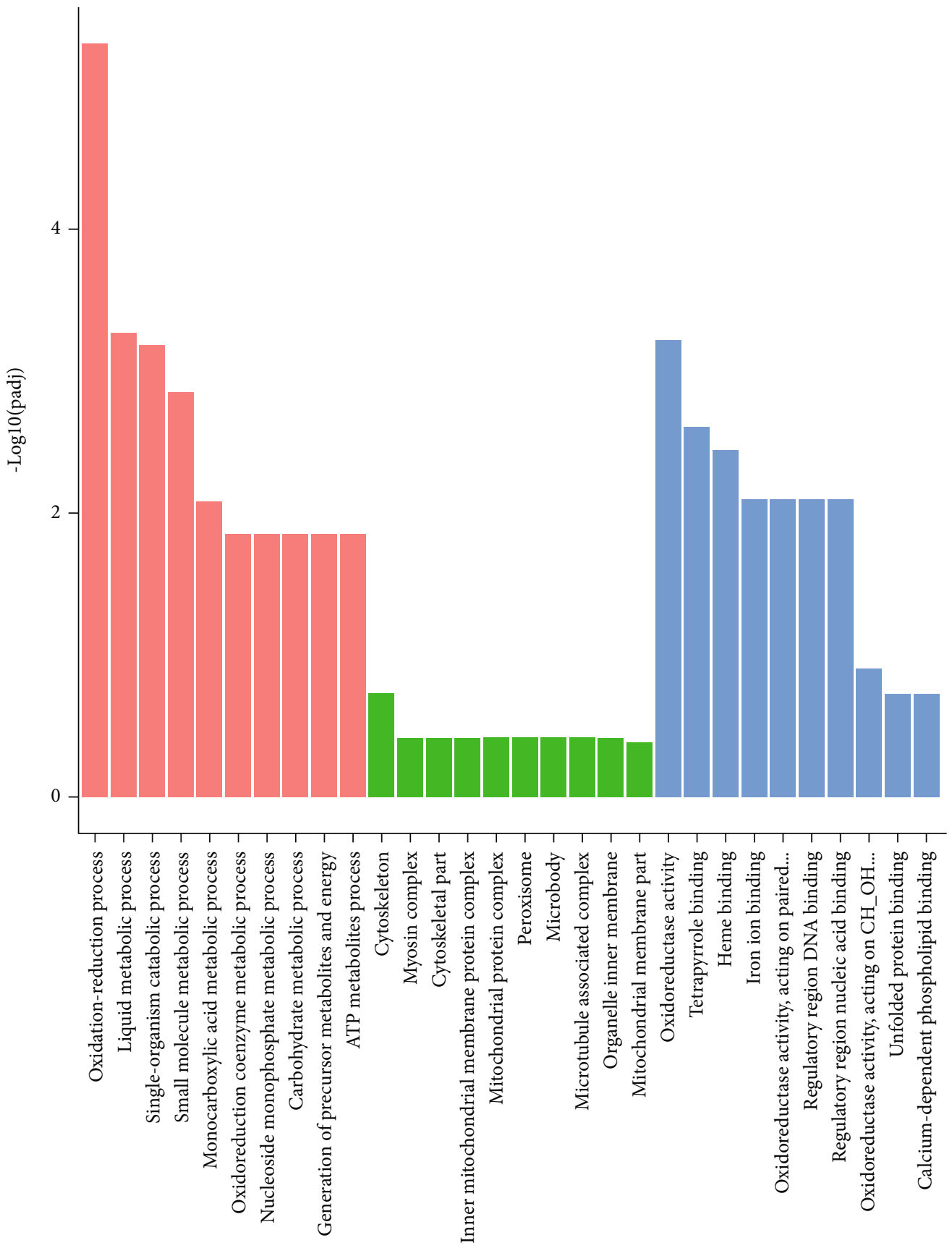

Description

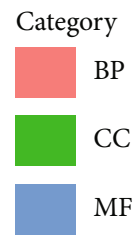

(b)

FIGURE 9: Effects of HFD and HRLP on related GO classification: (a) GO classification of DEGs between HFD and CN groups; (b) GO classification of DEGs between HRLP and HFD groups. 


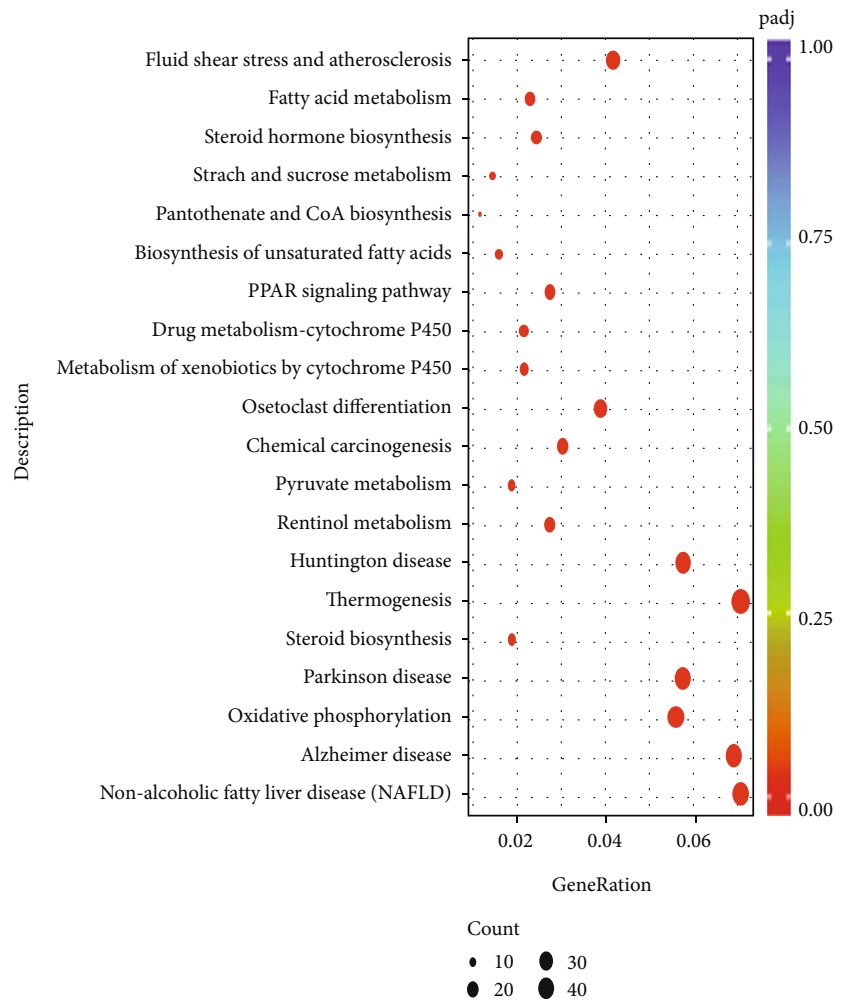

(a)

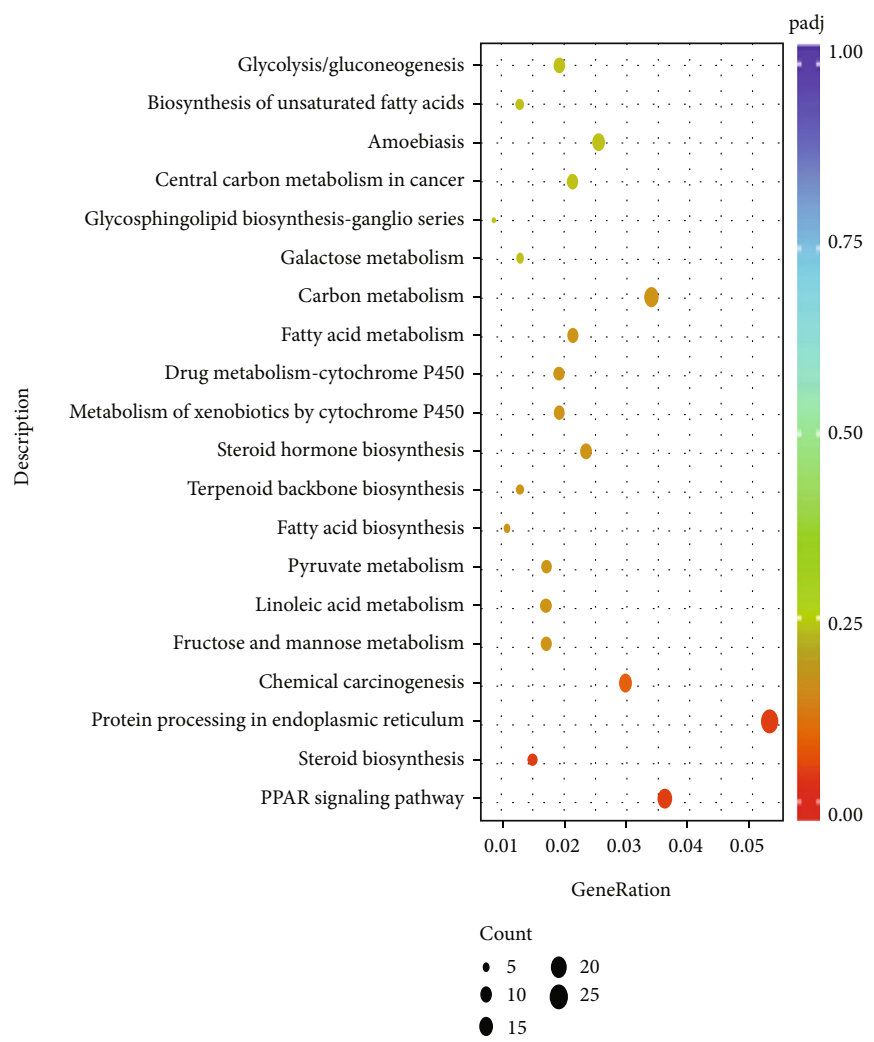

(b)

FIGURE 10: Effects of HFD and HRLP on related pathways: (a) KEGG analysis of DEGs between HFD and CN groups; (b) KEGG analysis of DEGs between HRLP and HFD groups. 


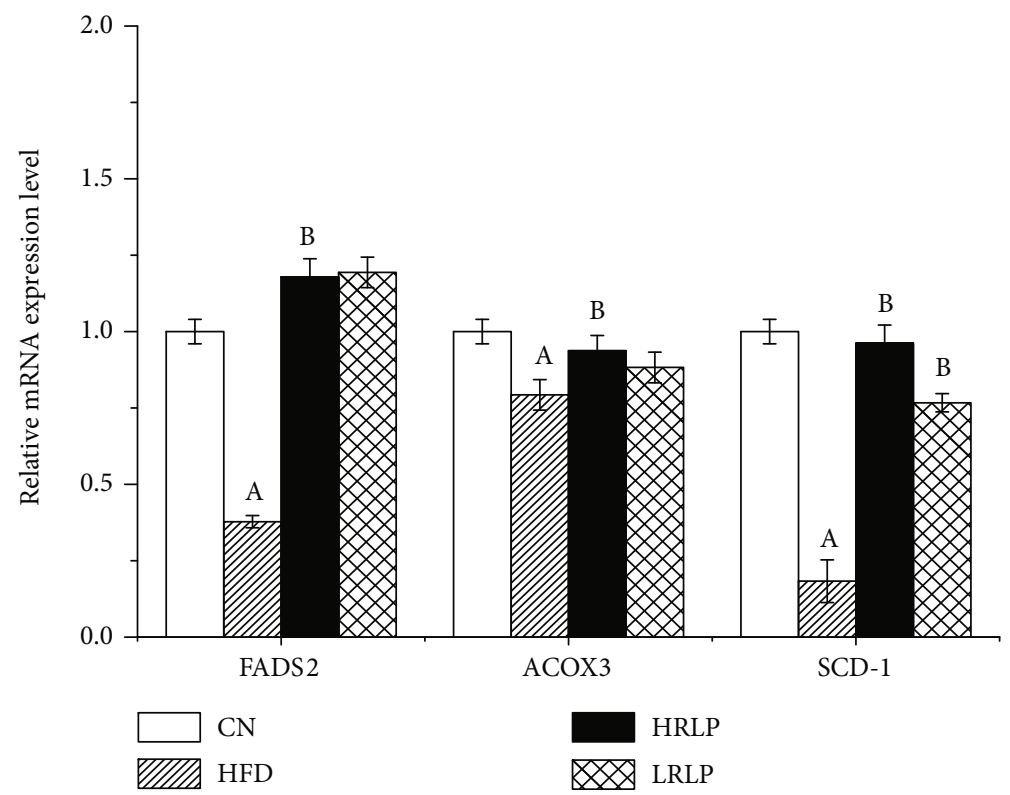

(a)

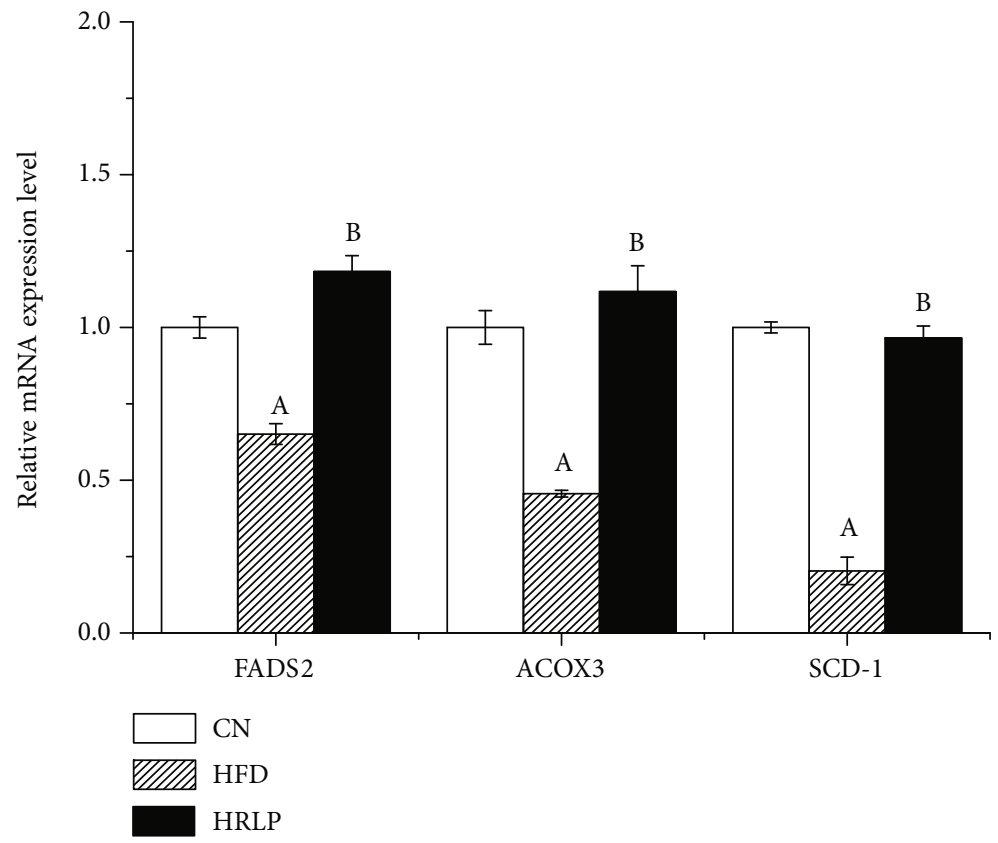

(b)

FIGURE 11: Effects of HFD and HRLP on liver gene expression of FADS2, ACOX3, and SCD-1. (a) mRNA expressions were determined by RNA-Seq, and set the fold change of the control group to 1 and then calculate the fold change for each group ( $n=3$ ). (b) mRNA expressions were determined by qRT-PCR, and set the fold change of the control group to 1 and then calculate the fold change for each group $(n=3)$; (a) significantly different from the corresponding normal chow $(\mathrm{CN})$ group $(P<0.05)$; (b) significantly different from the corresponding high-fat diet (HFD) group $(P<0.05)$.

profiles, and inhibited lipid accumulation in the liver by upregulation of FADS2, ACOX3, and SCD-1 involved in the lipid metabolic processes and the oxidative stress. RLPs with low molecular weight attenuated the HFD-induced dysfunction of fat metabolic and liver functions, as well as oxidative processes. The fat metabolic dysfunction was ameliorated by RLPs through the integration of the PPAR signaling pathway, suggesting a new route for possible treatment of hyper- lipidemia. RLPs had potential applications as a candidate in the functional food supplements for hyperlipidemia population.

\section{Data Availability}

The data used to support the findings of this study are available from the corresponding author upon request. 


\section{Conflicts of Interest}

The authors declare that there is no conflict of interests regarding the publication of this paper.

\section{Acknowledgments}

This work was a project supported by the Scientific Research Fund of Hunan Provincial Education Department (17B139).

\section{References}

[1] C. Yu, X. Dai, Q. Chen et al., "Hypolipidemic and antioxidant activities of polysaccharides from Rosae Laevigatae Fructus in rats," Carbohydrate Polymers, vol. 94, no. 1, pp. 56-62, 2013.

[2] Q. Zhan, Q. Wang, R. Lin et al., "Structural characterization and immunomodulatory activity of a novel acid polysaccharide isolated from the pulp of Rosa laevigata Michx fruit," International Journal of Biological Macromolecules, vol. 145, pp. 1080-1090, 2020.

[3] R. Hartemink and F. M. Rombouts, "Comparison of media for the detection of bifidobacteria, lactobacilli and total anaerobes from faecal samples," Journal of Microbiological Methods, vol. 36, no. 3, pp. 181-192, 1999.

[4] X. Li, W. Cao, Y. Shen et al., "Antioxidant compounds from Rosa laevigata fruits," Food Chemistry, vol. 130, no. 3, pp. 575-580, 2012.

[5] S. Zhang, Y. Qi, Y. Xu et al., "Protective effect of flavonoid-rich extract from Rosa laevigata Michx on cerebral ischemiareperfusion injury through suppression of apoptosis and inflammation," Neurochemistry International, vol. 63, no. 5, pp. 522-532, 2013.

[6] S. Chirumbolo, "Hormetic effect of Rosa laevigata Michx in CCl4-induced hepatotoxicity and the presumptive role of PPARs," Food and Chemical Toxicology, vol. 57, pp. 387-388, 2013.

[7] S. Zhang, L. Zheng, D. Dong et al., "Effects of flavonoids from Rosa laevigata Michx fruit against high-fat diet-induced nonalcoholic fatty liver disease in rats," Food Chemistry, vol. 141, no. 3, pp. 2108-2116, 2013.

[8] D. Dong, S. Zhang, L. Yin et al., "Protective effects of the total saponins from Rosa laevigata Michx fruit against carbon tetrachloride-induced acute liver injury in mice," Food and Chemical Toxicology, vol. 62, pp. 120-130, 2013.

[9] L. Chu, L. Yang, L. Lin et al., "Chemical composition, antioxidant activities of polysaccharide from pine needle (Pinus massoniana) and hypolipidemic effect in high-fat diet-induced mice," International Journal of Biological Macromolecules, vol. 125, pp. 445-452, 2019.

[10] X. Sun, C. Zhao, W. Pan, J. Wang, and W. Wang, "Carboxylate groups play a major role in antitumor activity of Ganoderma applanatum polysaccharide," Carbohydrate Polymers, vol. 123, pp. 283-287, 2015.

[11] N. Zhang, Y. Wang, J. Kan et al., "In vivo and in vitro antiinflammatory effects of water-soluble polysaccharide from Arctium lappa," International Journal of Biological Macromolecules, vol. 135, pp. 717-724, 2019.

[12] D. Belhaj, D. Frikha, K. Athmouni et al., "Box-Behnken design for extraction optimization of crude polysaccharides from Tunisian Phormidium versicolor cyanobacteria (NCC 466): partial characterization, in vitro antioxidant and antimicrobial activities," International Journal of Biological Macromolecules, vol. 105, pp. 1501-1510, 2017.

[13] Y. Li, D. Lin, B. Jiao et al., "Purification, antioxidant and hepatoprotective activities of polysaccharide from Cissus pteroclada Hayata," International Journal of Biological Macromolecules, vol. 77, pp. 307-313, 2015.

[14] D. Wang, C. Li, W. Fan, T. Yi, A. Wei, and Y. Ma, "Hypoglycemic and hypolipidemic effects of a polysaccharide from Fructus Corni in streptozotocin-induced diabetic rats," International Journal of Biological Macromolecules, vol. 133, pp. 420-427, 2019.

[15] W. L. Guo, M. Chen, W. L. Pan et al., "Hypoglycemic and hypolipidemic mechanism of organic chromium derived from chelation of Grifola frondosa polysaccharide-chromium (III) and its modulation of intestinal microflora in high fat-diet and STZ-induced diabetic mice," International Journal of Biological Macromolecules, vol. 145, pp. 1208-1218, 2020.

[16] L. Yang and L. Zhang, "Chemical structural and chain conformational characterization of some bioactive polysaccharides isolated from natural sources," Carbohydrate Polymers, vol. 76, pp. 349-361, 2009.

[17] C. S. Zhou, X. J. Yu, Y. Z. Zhang, R. H. He, and H. L. Ma, "Ultrasonic degradation, purification and analysis of structure and antioxidant activity of polysaccharide from Porphyra yezoensis Udea," Carbohydrate Polymers, vol. 87, pp. 20462051, 2012.

[18] Z. Zhang, X. Wang, M. Zhao, and H. Qi, "Free-radical degradation by $\mathrm{Fe}^{2+} / \mathrm{Vc} / \mathrm{H}_{2} \mathrm{O}_{2}$ and antioxidant activity of polysaccharide from Tremella fuciformis," Carbohydrate Polymers, vol. 112, pp. 578-582, 2014.

[19] Y. Xu, X. Zhang, X. Yan et al., "Characterization, hypolipidemic and antioxidant activities of degraded polysaccharides from Ganoderma lucidum," International Journal of Biological Macromolecules, vol. 135, pp. 706-716, 2019.

[20] W. Liu, H. Y. Wang, X. B. Pang, W. B. Yao, and X. D. Gao, "Characterization and antioxidant activity of two lowmolecular-weight polysaccharides purified from the fruiting bodies of Ganoderma lucidum," International Journal of Biological Macromolecules, vol. 46, no. 4, pp. 451-457, 2010.

[21] L. Q. Sun, C. H. Wang, Q. J. Shi, and C. H. Ma, "Preparation of different molecular weight polysaccharides from Porphyridium cruentum and their antioxidant activities," International Journal of Biological Macromolecules, vol. 42, pp. 42-47, 2009.

[22] X. Zha, J. Xiao, H. Zhang et al., "Polysaccharides in Laminaria japonica (LP): extraction, physicochemical properties and their hypolipidemic activities in diet-induced mouse model of atherosclerosis," Food Chemistry, vol. 134, pp. 244-252, 2012.

[23] X. Hou and W. Chen, "Optimization of extraction process of crude polysaccharides from wild edible BaChu mushroom by response surface methodology," Carbohydrate Polymers, vol. 72, pp. 67-74, 2008.

[24] X. Xie, J. Wang, and H. Zhang, "Characterization and antitumor activities of a water-soluble polysaccharide from Ampelopsis megalophylla," Carbohydrate Polymers, vol. 129, pp. 55-61, 2015.

[25] M. Meng, D. Cheng, L. Han, Y. Chen, and C. Wang, "Isolation, purification, structural analysis and immunostimulatory activity of water-soluble polysaccharides from Grifola Frondosa fruiting body," Carbohydrate Polymers, vol. 157, pp. 11341143, 2017. 
[26] K. Feng, W. Chen, L. Sun et al., "Optimization extraction, preliminary characterization and antioxidant activity in vitro of polysaccharides from Stachys sieboldii Miq. tubers," Carbohydrate Polymers, vol. 125, pp. 45-52, 2015.

[27] L. H. Lin, J. H. Xie, S. C. Liu, M. Y. Shen, W. Tang, and M. Y. Xie, "Polysaccharide from Mesona chinensis: extraction optimization, physicochemical characterizations and antioxidant activities," International Journal of Biological Macromolecules, vol. 99, pp. 665-673, 2017.

[28] S. Xu, Y. Dou, B. Ye et al., "Ganoderma lucidum polysaccharides improve insulin sensitivity by regulating inflammatory cytokines and gut microbiota composition in mice," Journal of Functional Foods, vol. 38, pp. 545-552, 2017.

[29] Z. Gao, C. Zhang, C. Tian et al., "Characterization, antioxidation, anti-inflammation and renoprotection effects of selenized mycelia polysaccharides from Oudemansiella radicata," Carbohydrate Polymers, vol. 181, pp. 1224-1234, 2018.

[30] Y. Chen, X. Jiang, H. Xie, X. Li, and L. Shi, "Structural characterization and antitumor activity of a polysaccharide from Ramulus mori," Carbohydrate Polymers, vol. 190, pp. 232239, 2018.

[31] Y. Gong, J. Zhang, F. Gao et al., "Structure features and in vitro hypoglycemic activities of polysaccharides from different species of Maidong," Carbohydrate Polymers, vol. 173, pp. 215222, 2017.

[32] B. Yang, K. N. Prasad, and Y. Jiang, "Structure identification of a polysaccharide purified from litchi (Litchi chinensis Sonn.) pulp," Carbohydrate Polymers, vol. 137, pp. 570-575, 2016.

[33] C. Zheng, Q. Dong, Z. Du, P. Wang, and K. Ding, "Structural elucidation of a polysaccharide from Chrysanthemum morifolium flowers with anti-angiogenic activity," International Journal of Biological Macromolecules, vol. 79, pp. 674-680, 2015.

[34] S. G. Sousa, L. A. Oliveira, D. A. Magalhães et al., "Chemical structure and anti-inflammatory effect of polysaccharide extracted from Morinda citrifolia Linn (Noni)," Carbohydrate Polymers, vol. 197, pp. 515-523, 2018.

[35] X. Wang, X. Zhao, Y. Lv et al., "Extraction, isolation and structural characterization of a novel polysaccharide from Cyclocarya paliurus," International Journal of Biological Macromolecules, vol. 132, pp. 864-870, 2019.

[36] J. K. Bhatia, B. S. Kaith, and S. Kalia, "Polysaccharide hydrogels: synthesis, characterization, and applications," in Polysaccharide Based Graft Copolymers, pp. 271-290, Springer, 2013.

[37] D. Suvakanta, M. P. Narsimha, D. Pulak, C. Joshabir, and D. Biswajit, "Optimization and characterization of purified polysaccharide from Musa sapientum L. as a pharmaceutical excipient," Food Chemistry, vol. 149, pp. 76-83, 2014.

[38] E. N. Frankel and A. S. Meyer, "The problems of using onedimensional methods to evaluate multifunctional food and biological antioxidants," Journal of the Science of Food and Agriculture, vol. 80, pp. 1925-1941, 2000.

[39] S. Rivas, B. Gullón, P. Gullón, J. L. Alonso, and J. C. Parajó, "Manufacture and properties of bifidogenic saccharides derived from wood mannan," Journal of Agricultural and Food Chemistry, vol. 60, no. 17, pp. 4296-4305, 2012.

[40] B. C. Lee, J. T. Baea, H. B. Pyo et al., "Biological activities of the polysaccharides produced from submerged culture of the edible Basidiomycete Grifola frondosa," Enzyme and Microbial Technology, vol. 32, no. 5, pp. 574-581, 2003.

[41] Y. Teng, Y. Wang, Y. Tian et al., "Lactobacillus plantarum LP104 ameliorates hyperlipidemia induced by AMPK path- ways in C57BL/6N mice fed high-fat diet," Journal of Functional Foods, vol. 64, p. 103665, 2020.

[42] Q. Chen, L. Q. Niu, C. F. Hua et al., "Chronic dexamethasone exposure markedly decreased the hepatic triglyceride accumulation in growing goats," General and Comparative Endocrinology, vol. 259, pp. 115-121, 2018.

[43] M. A. Micallef and M. L. Garg, "Beyond blood lipids: phytosterols, statins and omega-3 polyunsaturated fatty acid therapy for hyperlipidemia," Journal of Nutritional Biochemistry, vol. 20, no. 12, pp. 927-939, 2009.

[44] Y. Ru, X. Chen, J. Wang et al., "Polysaccharides from Tetrastigma hemsleyanum Diels et Gilg: extraction optimization, structural characterizations, antioxidant and antihyperlipidemic activities in hyperlipidemic mice," International Journal of Biological Macromolecules, vol. 125, pp. 1033-1041, 2019.

[45] H. I. Lee and M. K. Lee, "Coordinated regulation of scopoletin at adipose tissue-liver axis improved alcohol-induced lipid dysmetabolism and inflammation in rats," Toxicology Letters, vol. 237, no. 3, pp. 210-218, 2015.

[46] Y. Hayashi, A. Shimamura, T. Ishikawa, Y. Fujiwara, and I. Ichi, "FADS2 inhibition in essential fatty acid deficiency induces hepatic lipid accumulation via impairment of very low-density lipoprotein (VLDL) secretion," Biochemical and Biophysical Research Communications, vol. 496, no. 2, pp. 549-555, 2018.

[47] M. T. Flowers and J. M. Ntambi, "Role of stearoyl-coenzyme A desaturase in regulating lipid metabolism," Current Opinion in Lipidology, vol. 19, no. 3, pp. 248-256, 2008.

[48] M. Miyazaki, Y. C. Kim, and J. M. Ntambi, “A lipogenic diet in mice with a disruption of the stearoyl-CoA desaturase 1 gene reveals a stringent requirement of endogenous monounsaturated fatty acids for triglyceride synthesis," Journal of Lipid Research, vol. 42, no. 7, pp. 1018-1024, 2001.

[49] P. Dobrzyn, A. Dobrzyn, M. Miyazaki et al., "Stearoyl-CoA desaturase 1 deficiency increases fatty acid oxidation by activating AMP-activated protein kinase in liver," PNAS, vol. 101, no. 17, pp. 6409-6414, 2004.

[50] M. T. Flowers, A. K. Groen, A. T. Oler et al., "Cholestasis and hypercholesterolemia in SCD1-deficient mice fed a low-fat, high-carbohydrate diet," Journal of Lipid Research, vol. 47, no. 12 , pp. $2668-2680,2006$. 